Supplement of Hydrol. Earth Syst. Sci., 18, 2669-2678, 2014

http://www.hydrol-earth-syst-sci.net/18/2669/2014/

doi:10.5194/hess-18-2669-2014-supplement

(C) Author(s) 2014. CC Attribution 3.0 License.

(c) (i)

Hydrology and Earth System

Sciences

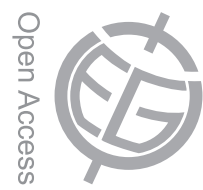

Supplement of

\title{
Global meteorological drought - Part 2: Seasonal forecasts
}

E. Dutra et al.

Correspondence to: E. Dutra (emanuel.dutra@ecmwf.int) 


\title{
Supplementary material
}

\section{Global meteorological drought: Part II - Seasonal forecasts}

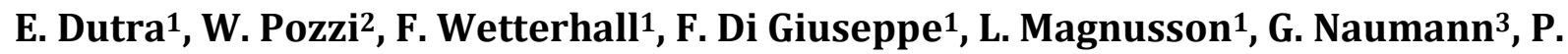 \\ Barbosa $^{3}$, J. Vogt ${ }^{3}$, and F. Pappenberger ${ }^{1}$ \\ [1]\{European Centre for Medium-Range Weather Forecasts, Reading, United Kingdom\} \\ [2]\{Group on Earth Observations, Geneva, Switzerland $\}$ \\ [3]\{Joint Research Centre, Institute for Environment and Sustainability, Ispra, Italy $\}$
}

Correspondence to: E. Dutra (emanuel.dutra@ecmwf.int)

\section{List of figures}

Figure S1. Regions used in the analysis adapted from Giorgi and Francisco (2000).............. 3

Figure S2. As Figure 1 but for the Amazon region (AMZ). ............................................. 4

Figure S3. As Figure 1 but for the Australia region (AUS) …..........................................

Figure S4. As Figure 1 but for the Central America region (CAM) ................................ 6

Figure S5. As Figure 1 but for the Central Asia region (CAS) .......................................... 7

Figure S6. As Figure 1 but for the Central North America region (CNA), ............................ 8

Figure S7. As Figure 1 but for the East Africa region (EAF) . ..........................................

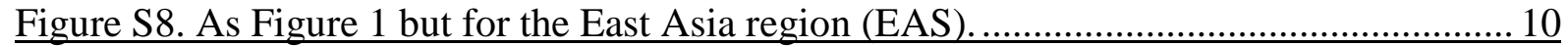

Figure S9. As Figure 1 but for the Eastern North America region (ENA). ........................ 11

Figure S10. As Figure 1 but for the Mediterranean region (MED)..................................... 12

Figure S11. As Figure 1 but for the North Asia region (NAS) . ................................... 13

Figure S12. As Figure 1 but for the Northern Europe region (NEU)............................... 14 
Figure S13. As Figure 1 but for the South Africa region (SAF)..................................... 15

Figure S14. As Figure 1 but for the South Asia region (SAS) .................................. 16

Figure S15. As Figure 1 but for the South East Asia region (CNA) ............................... 17

Figure S16. As Figure 1 but for the South South America region (SSA), ......................... 18

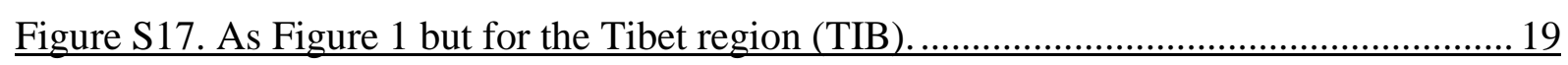

Figure S18. As Figure 1 but for the West Africa region (WAF). ................................. 20

Figure S19. As Figure 1 but for the West North America region (WNA) ........................ 21

Figure S20. Drough onset frequency distributions of (a) brier score, (b) reliability, (c) resolution, (d) sharpness and (e) brier skill score for the SPI forecasts produced by GPCC S4 (red0, GPCC CLM (black), ERAI S4 (blue) and ERAI CLM (gray). The statististics are based only on land points (similar to Yuan and Wood (2013)), and the reference forecasts for the brier skill score was the climatological frequency of the verification dataset (GPCC).......... 22

Figure S21. Seasonal forecasts of 6-month SPI in the Horn of Africa region (3S-12N, 40E52E) given by GPCC S4 (blue) and GPCC CLM (black), and the GPCC monitoring (red) issued in September 2011 (top left), October 2011 (top right), February 2012 (bottom left) and March 2012 (bottom right). . The solid lines represent the ensemble mean forecasts of GPCC $\underline{\text { S4 (blue) and GPCC CLM (black), and the dashed blue line the GPCC S4 ensemble mean }}$ rescaled. The shaded areas represent the ensemble distribution between the percentiles 30 to $\underline{70 \text { (dark shading) and minimum to maxim (light shading). The horizontal dotted lines denote }}$ the $-0.8,0$ and 0.8 SPI values, and the vertical dotted line forecast issue date. 23

Figure S22. Seasonal forecasts of SPI-6 given by GPCC S4 issued in October 2010 and valid for March 2011: ensemble mean (top left), ensemble mean rescaled (top right), probability of

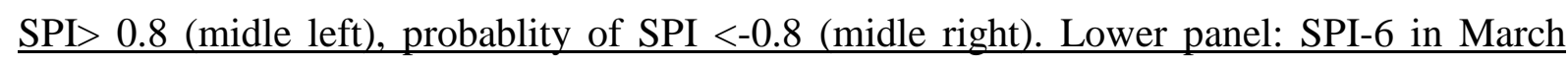
2011 from GPCC. In all maps gray denote grid-point where the SPI is not defined.............. 24

Figure S23. As Figure S21 but for the the SPI-6 forecasts issued in March, May, July and August 2012 for the U.S. Great Plains region (35N-45N, 110W-90W)........................... 25

Figure S24. As Figure S22 but for the the SPI-6 forecasts issued in April 2012 and valid for August 2012 in the U.S. Great Plains region (35N-45N, 110W-90W)............................. 26 


\section{Figures}

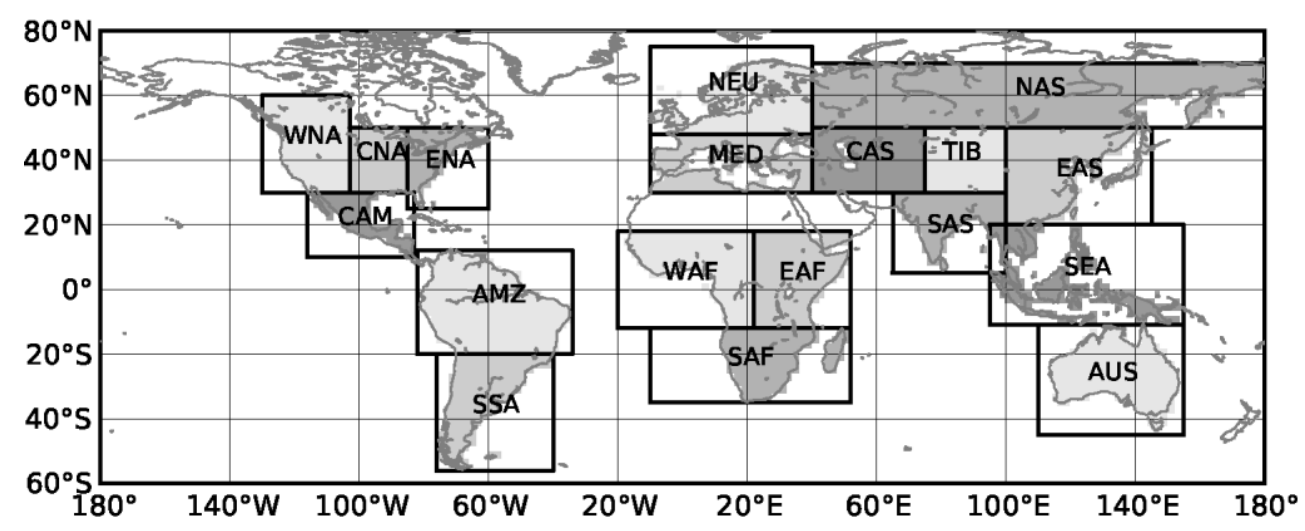

Figure S1. Regions used in the analysis adapted from Giorgi and Francisco (2000). 

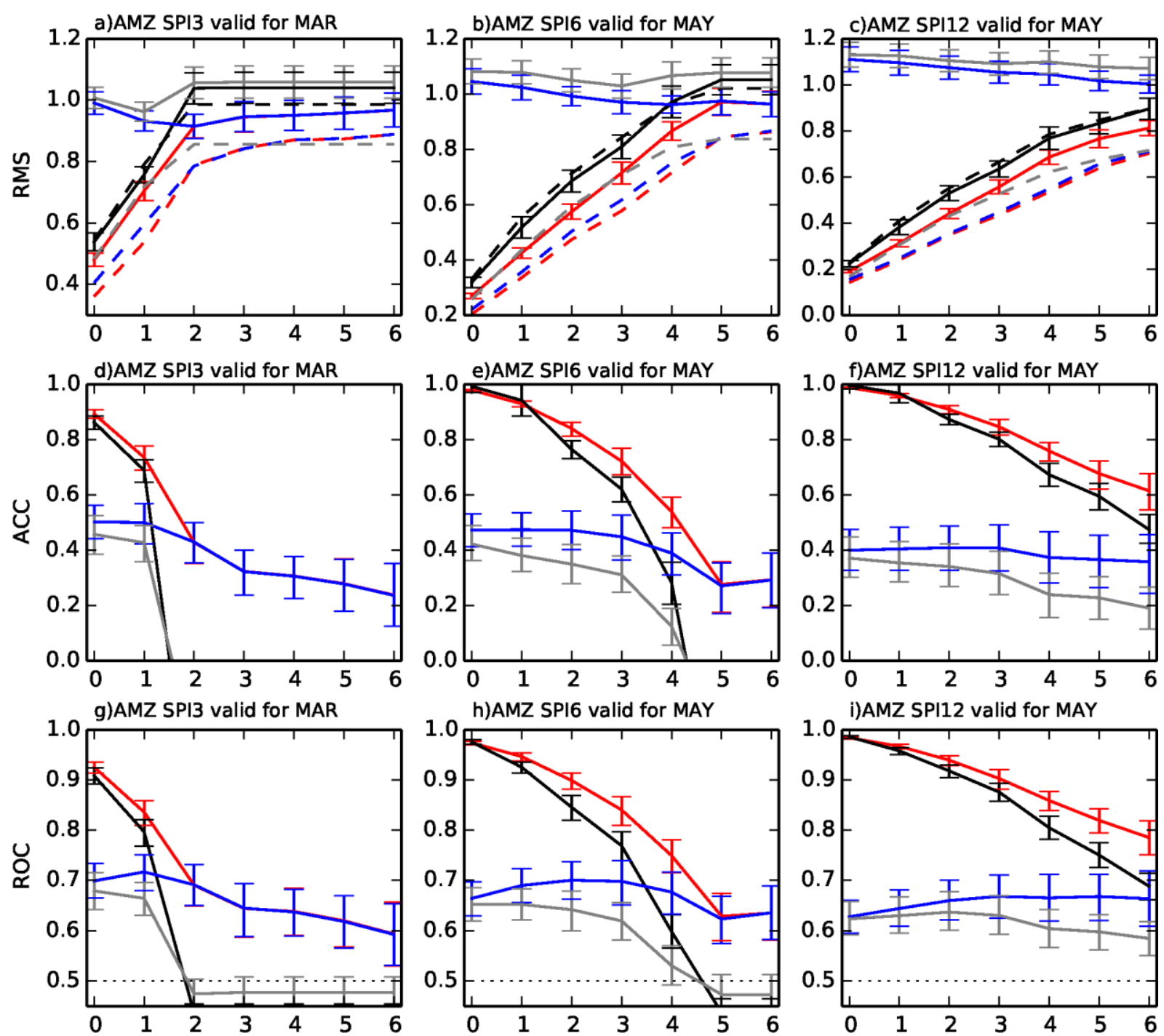

i)AMZ SPI12 valid for MAY

Forecast lead time (months)

Forecast lead time (months)

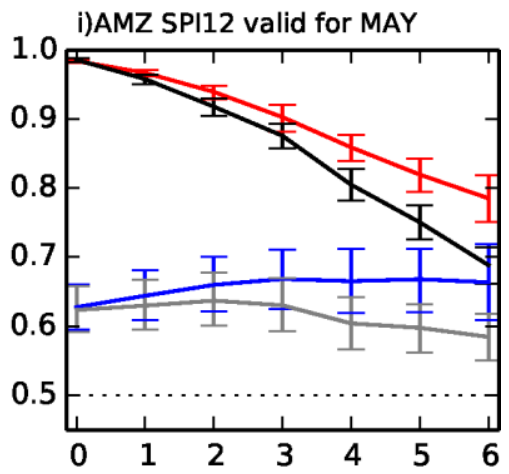

Forecast lead time (months)

FI GPCC S4 FI GPCC CLM FI ERAI S4 FI ERAI CLM

Figure S2. As Figure 1 but for the Amazon region (AMZ). 

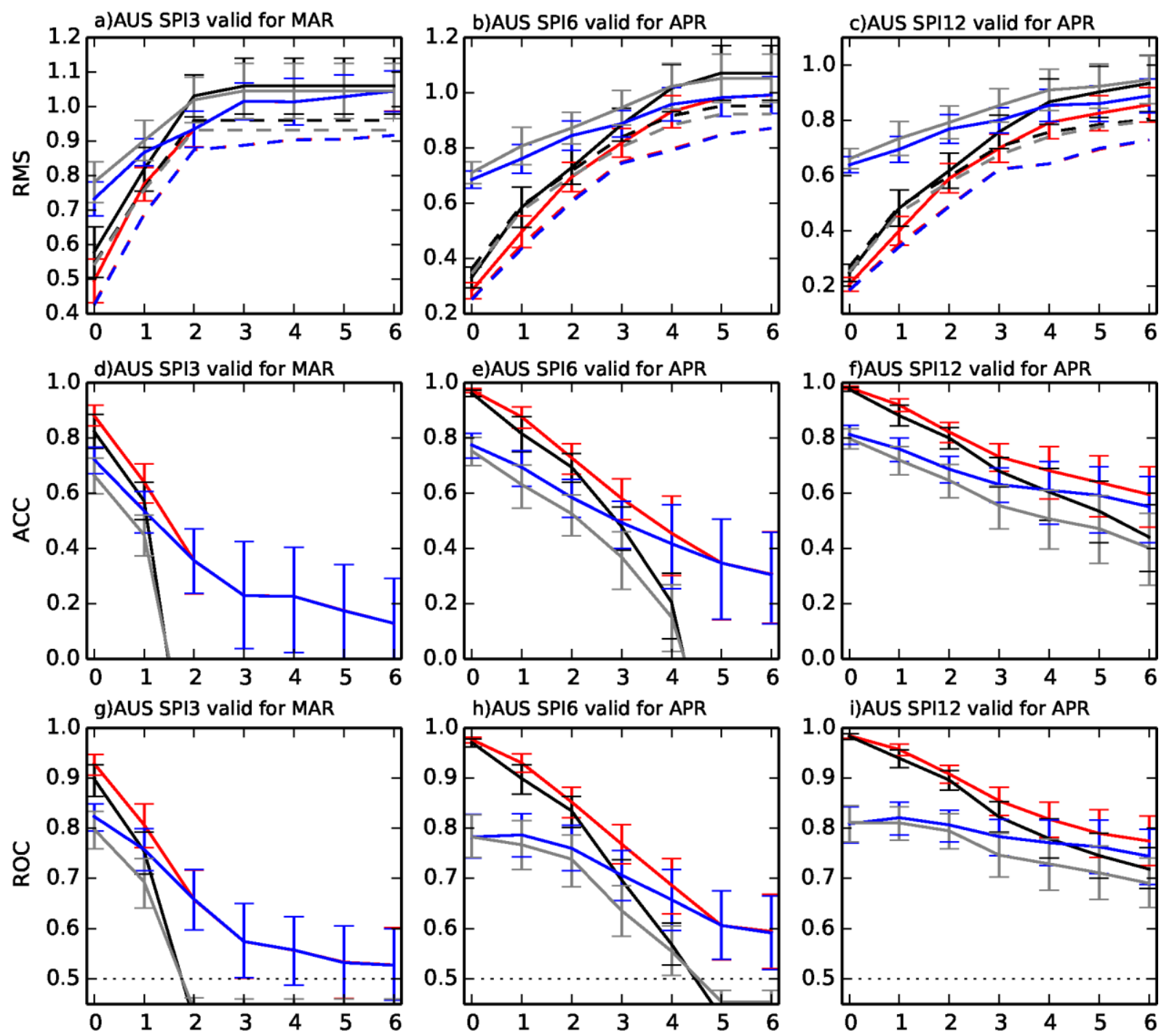

Forecast lead time (months)

Forecast lead time (months) Forecast lead time (months)

FI GPCC S4 FI GPCC CLM FA ERAI S4 FI ERAI CLM

Figure S3. As Figure 1 but for the Australia region (AUS) 

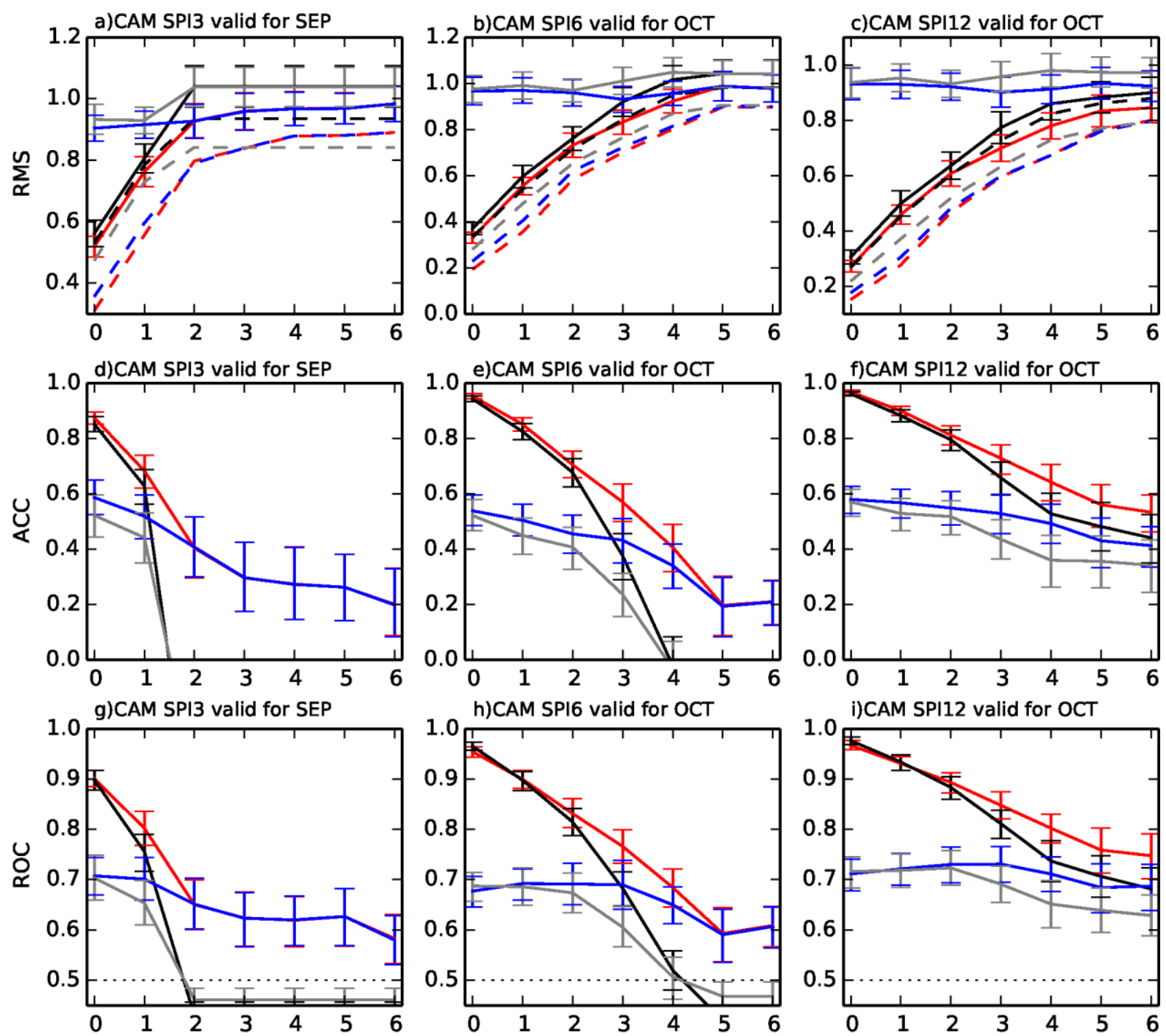

Forecast lead time (months)

Forecast lead time (months) Forecast lead time (months)

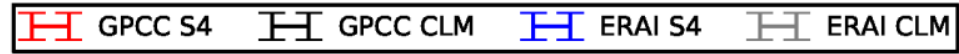

Figure S4. As Figure 1 but for the Central America region (CAM). 

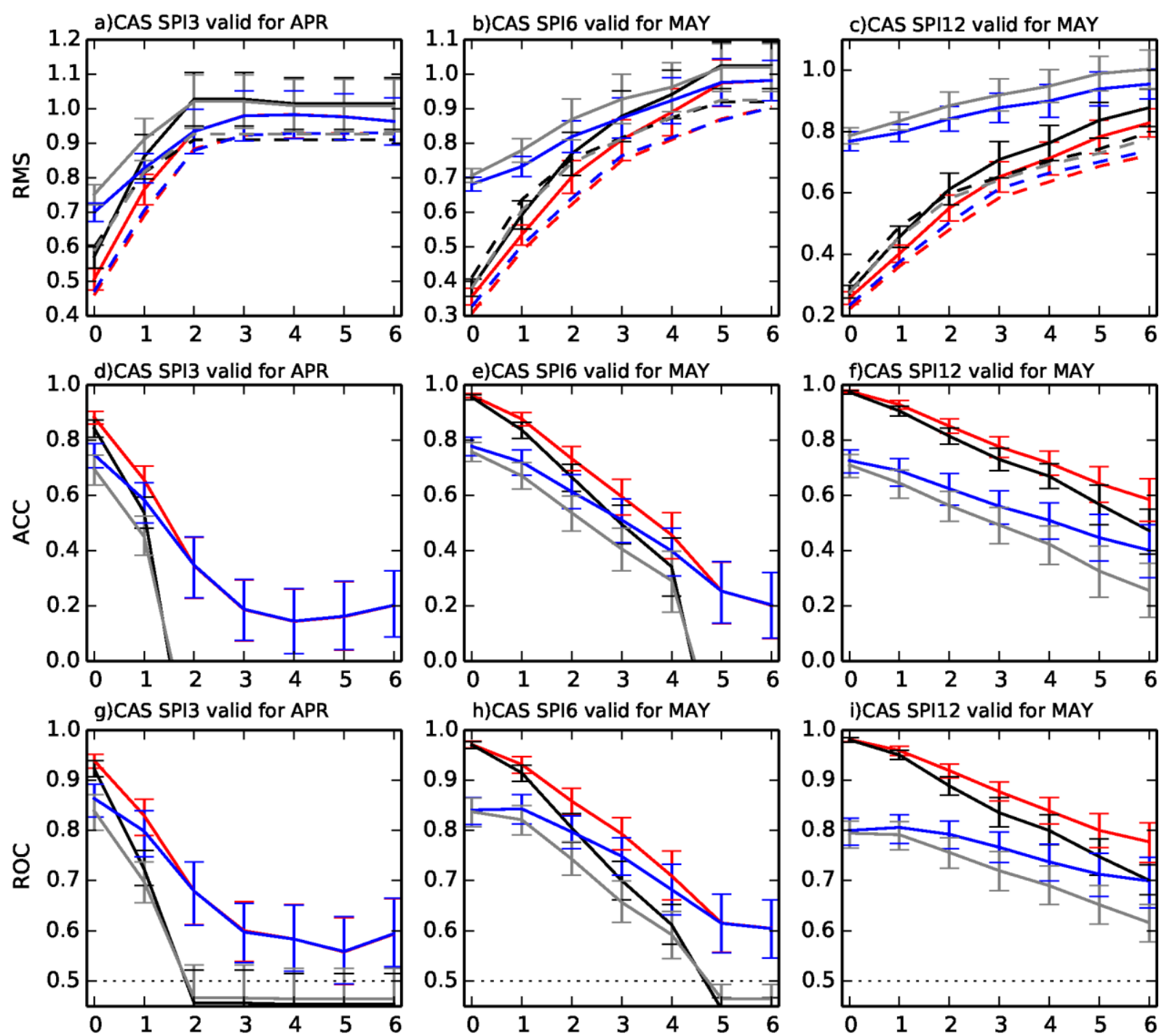

Forecast lead time (months)

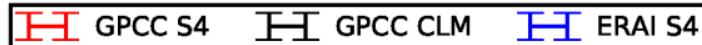

FI ERAI CLM

Figure S5. As Figure 1 but for the Central Asia region (CAS). 

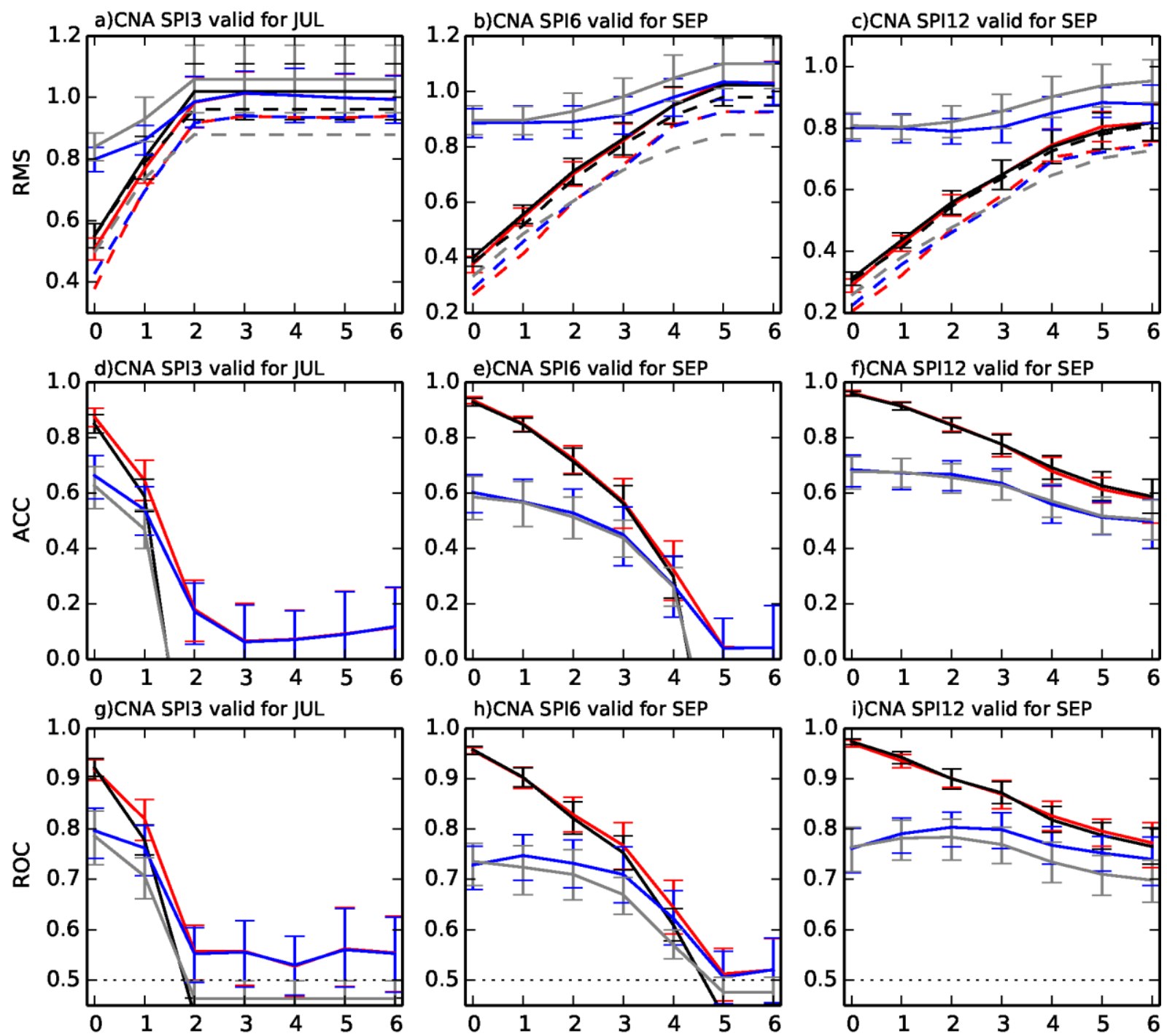

Forecast lead time (months)

Forecast lead time (months) Forecast lead time (months) FI GPCC S4 FA GPCC CLM FA ERAI S4 F士 ERAI CLM

Figure S6. As Figure 1 but for the Central North America region (CNA). 

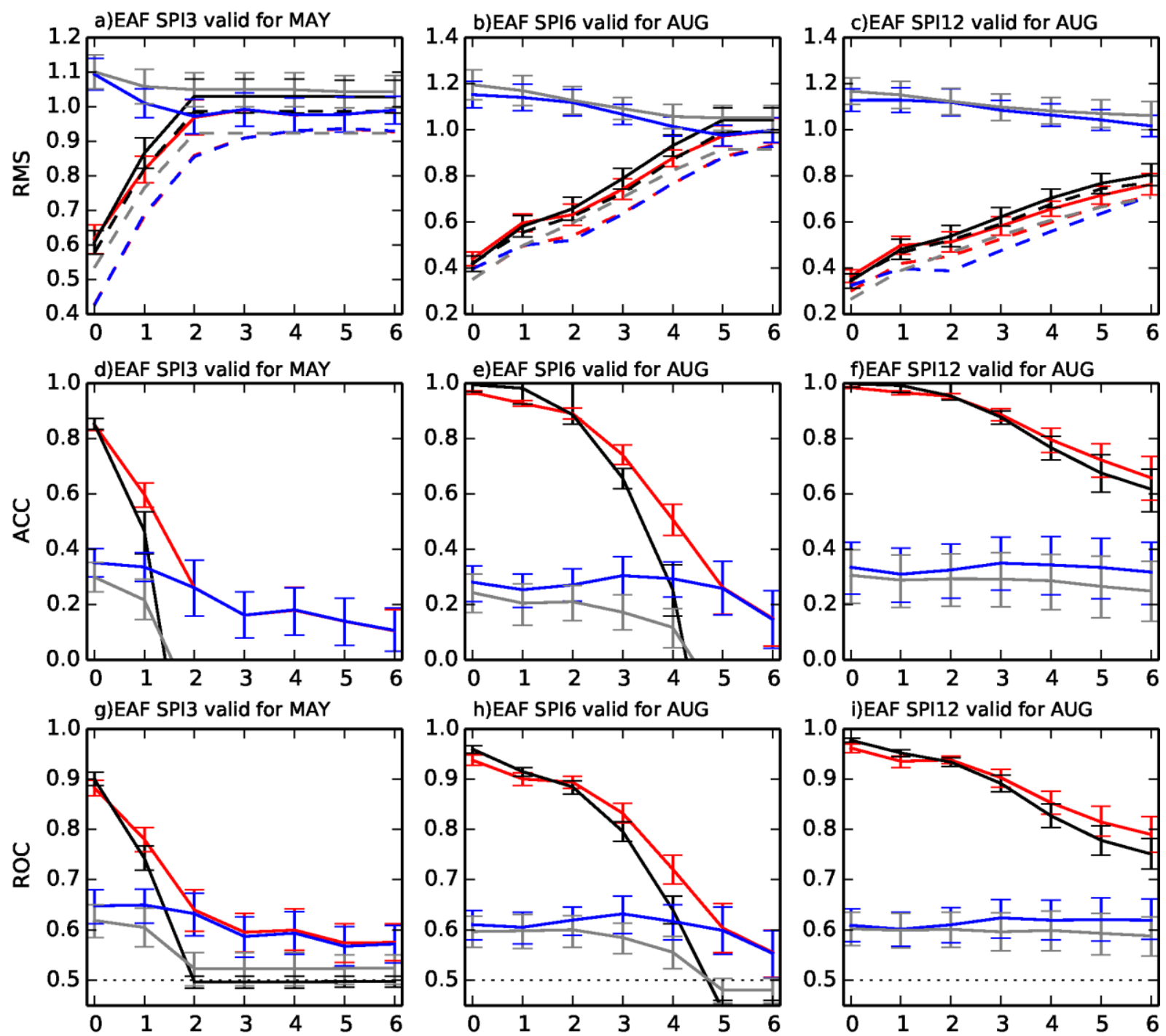

Forecast lead time (months)

Forecast lead time (months) Forecast lead time (months)

FI GPCC S4 FI GPCC CLM FA ERAI S4 FI ERAI CLM

Figure S7. As Figure 1 but for the East Africa region (EAF). 

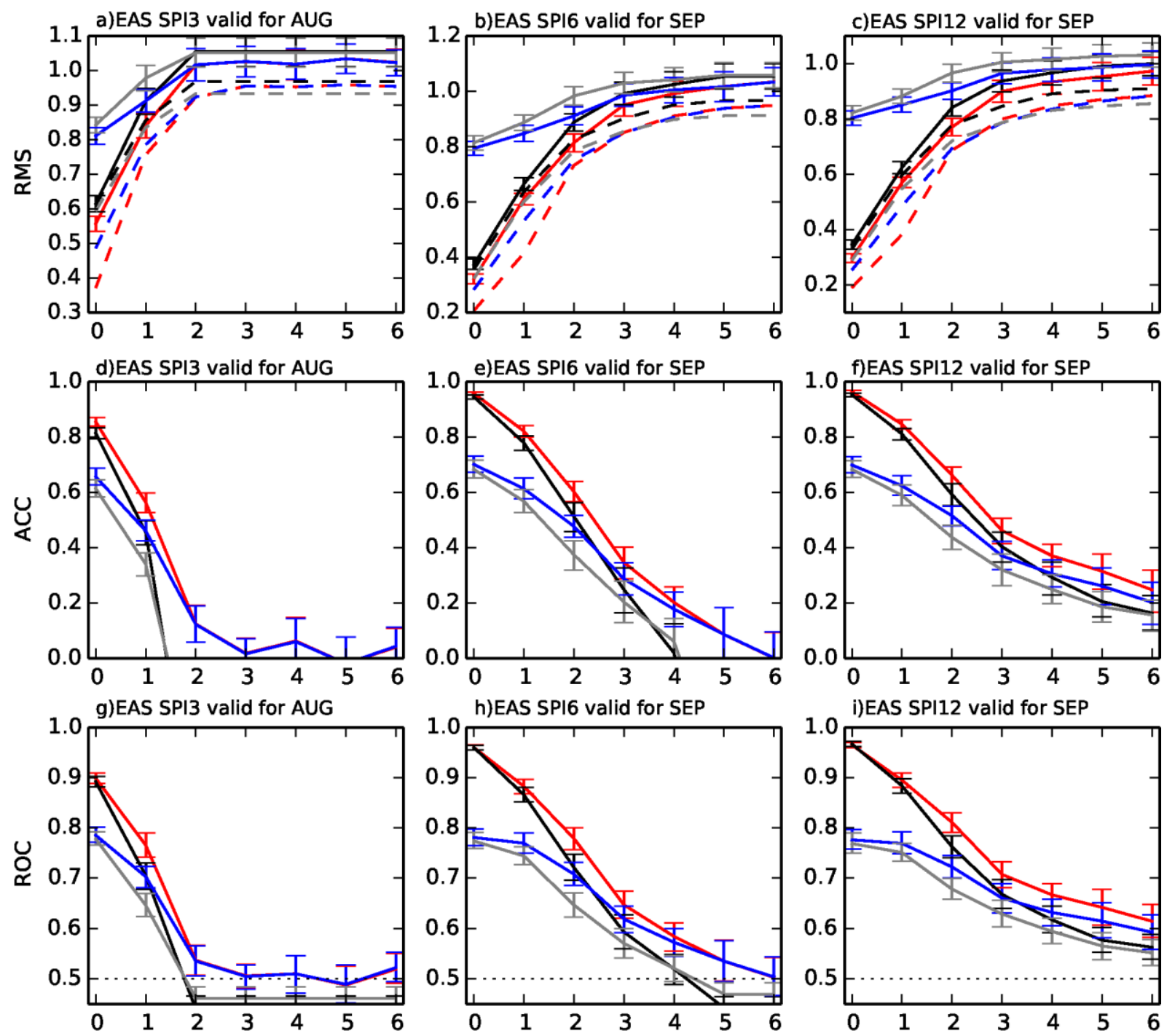

Forecast lead time (months)

Forecast lead time (months) Forecast lead time (months) F王 GPCC S4 FA GPCC CLM F士 ERAI S4 F士 ERAI CLM

Figure S8. As Figure 1 but for the East Asia region (EAS). 

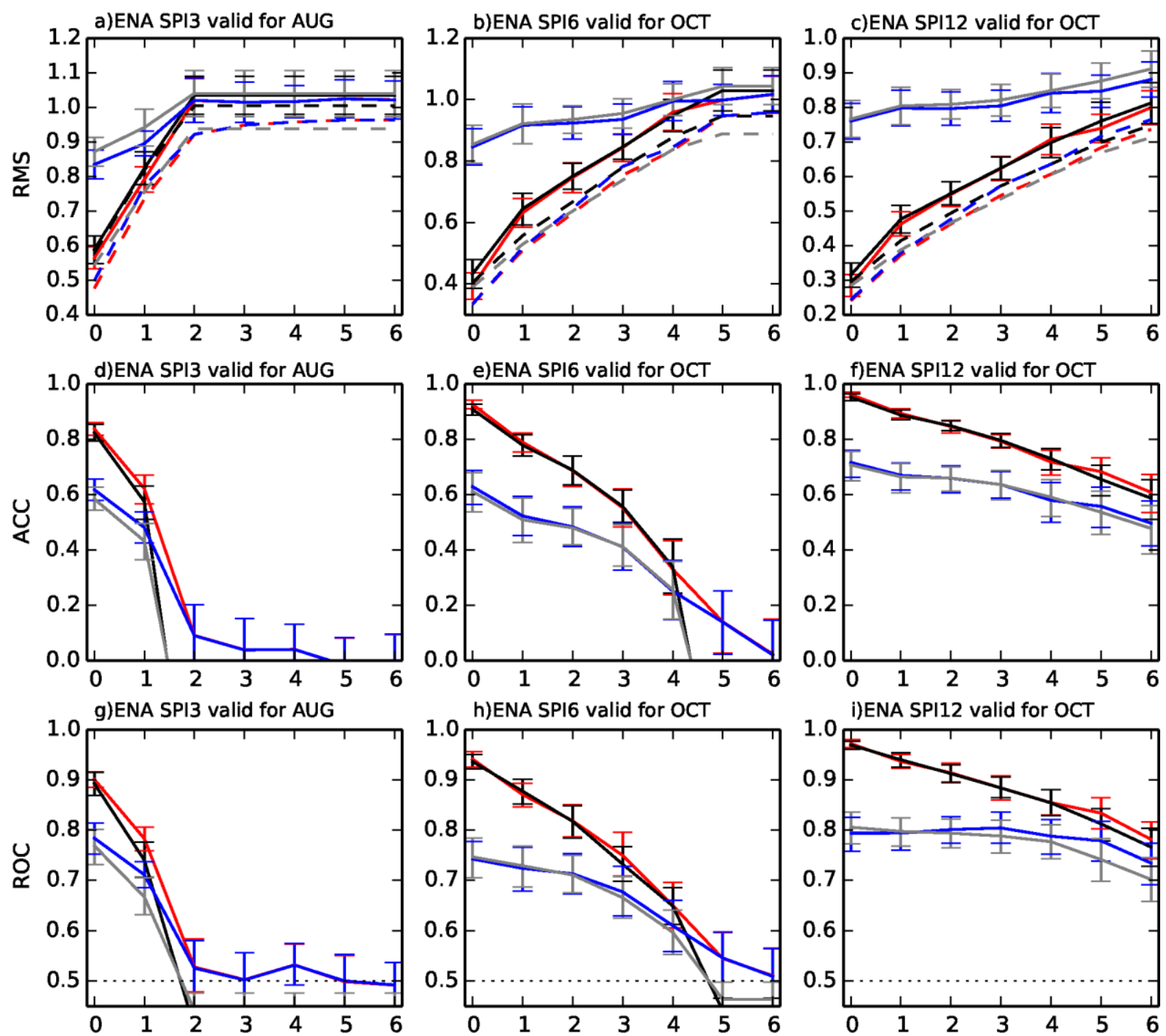

Forecast lead time (months)

Forecast lead time (months) Forecast lead time (months)

FI GPCC S4

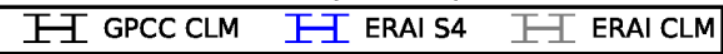

Figure S9. As Figure 1 but for the Eastern North America region (ENA). 

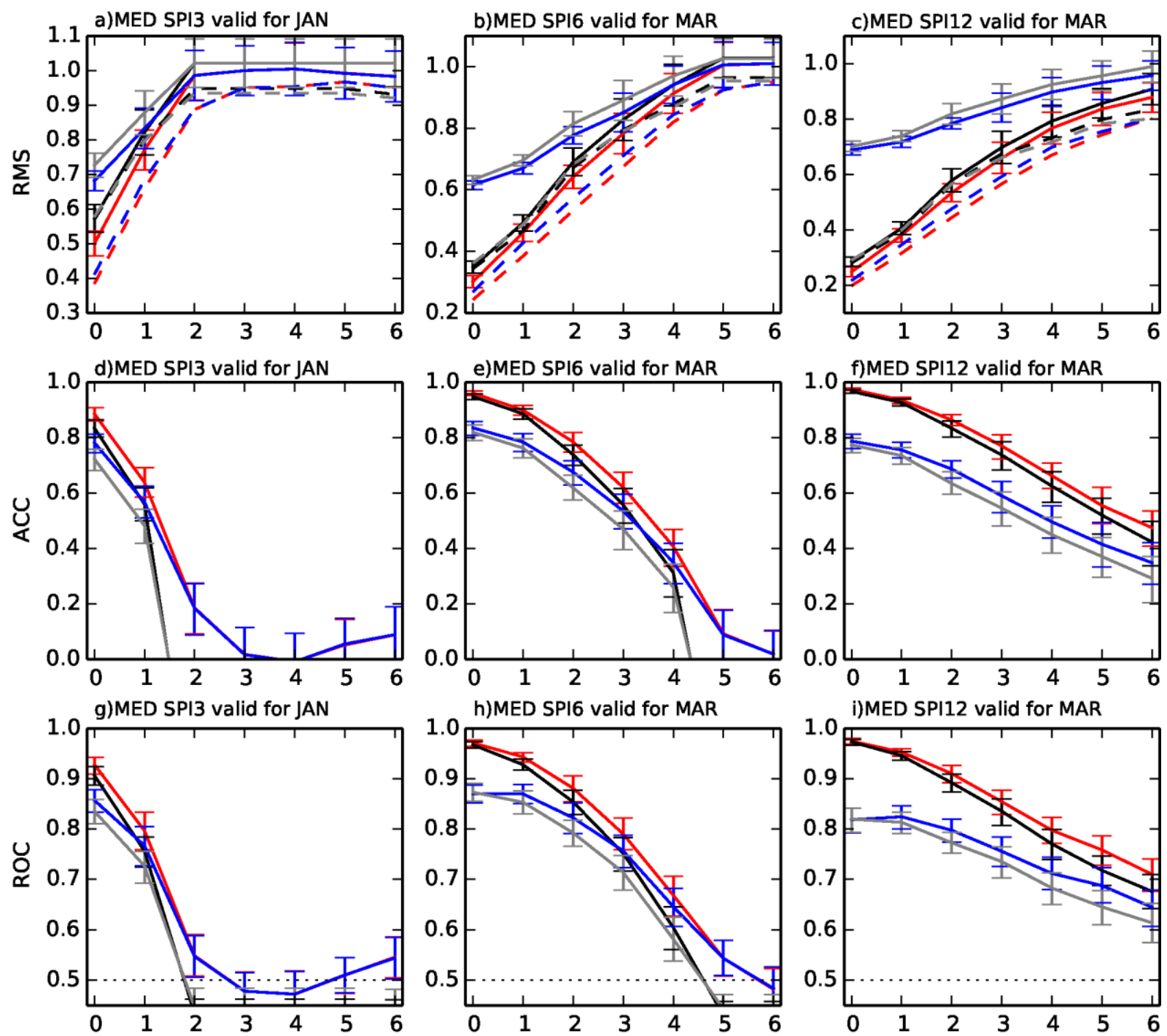

Forecast lead time (months)

Forecast lead time (months) Forecast lead time (months) FI GPCC 54 FI GPCC CLM IFI ERAI S4 IF ERAI CLM

Figure S10. As Figure 1 but for the Mediterranean region (MED). 

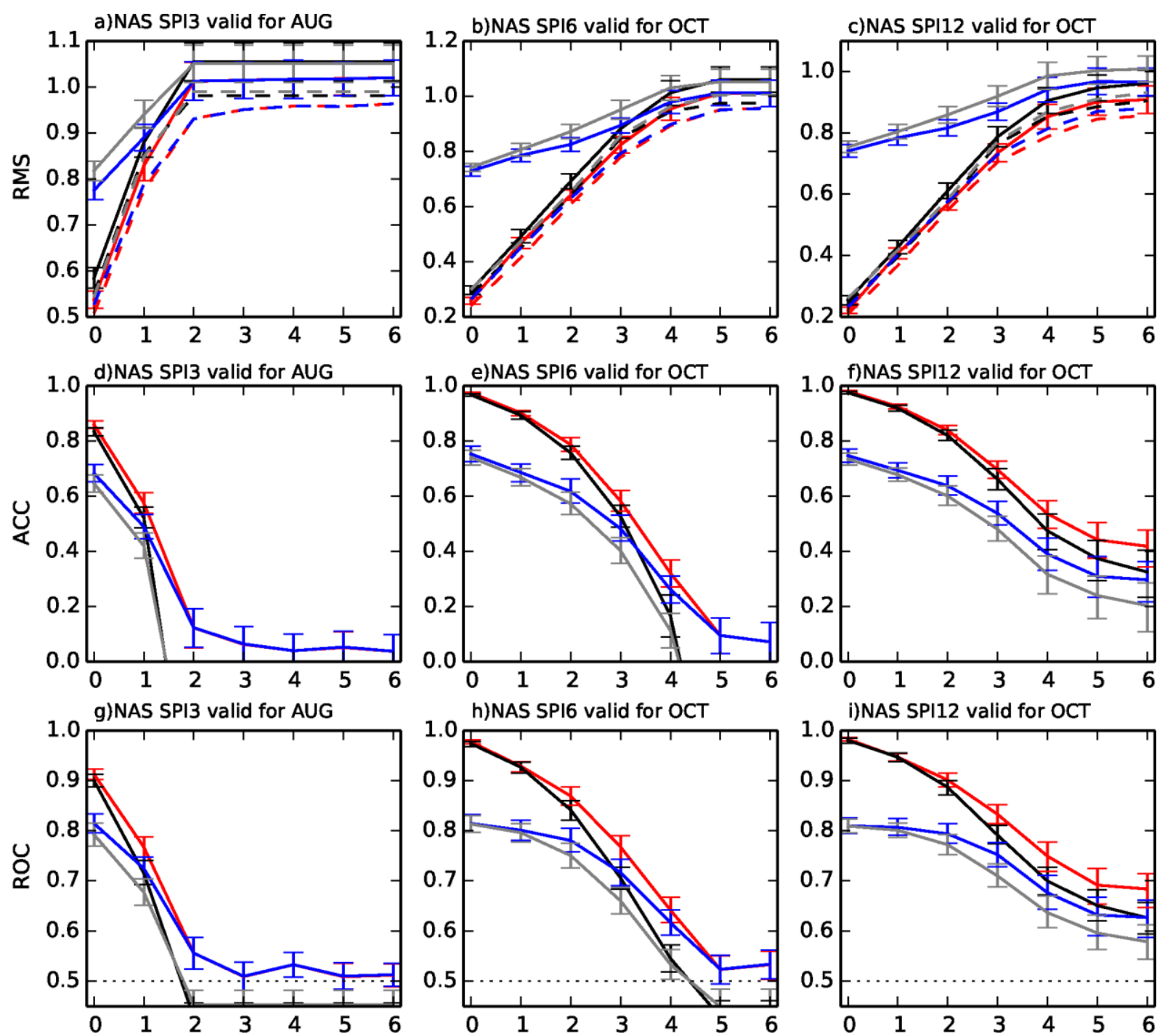

Forecast lead time (months)

Forecast lead time (months) Forecast lead time (months)

F巫 GPCC S4 FA GPCC CLM F任 ERAI S4

FI ERAI CLM

Figure S11. As Figure 1 but for the North Asia region (NAS). 

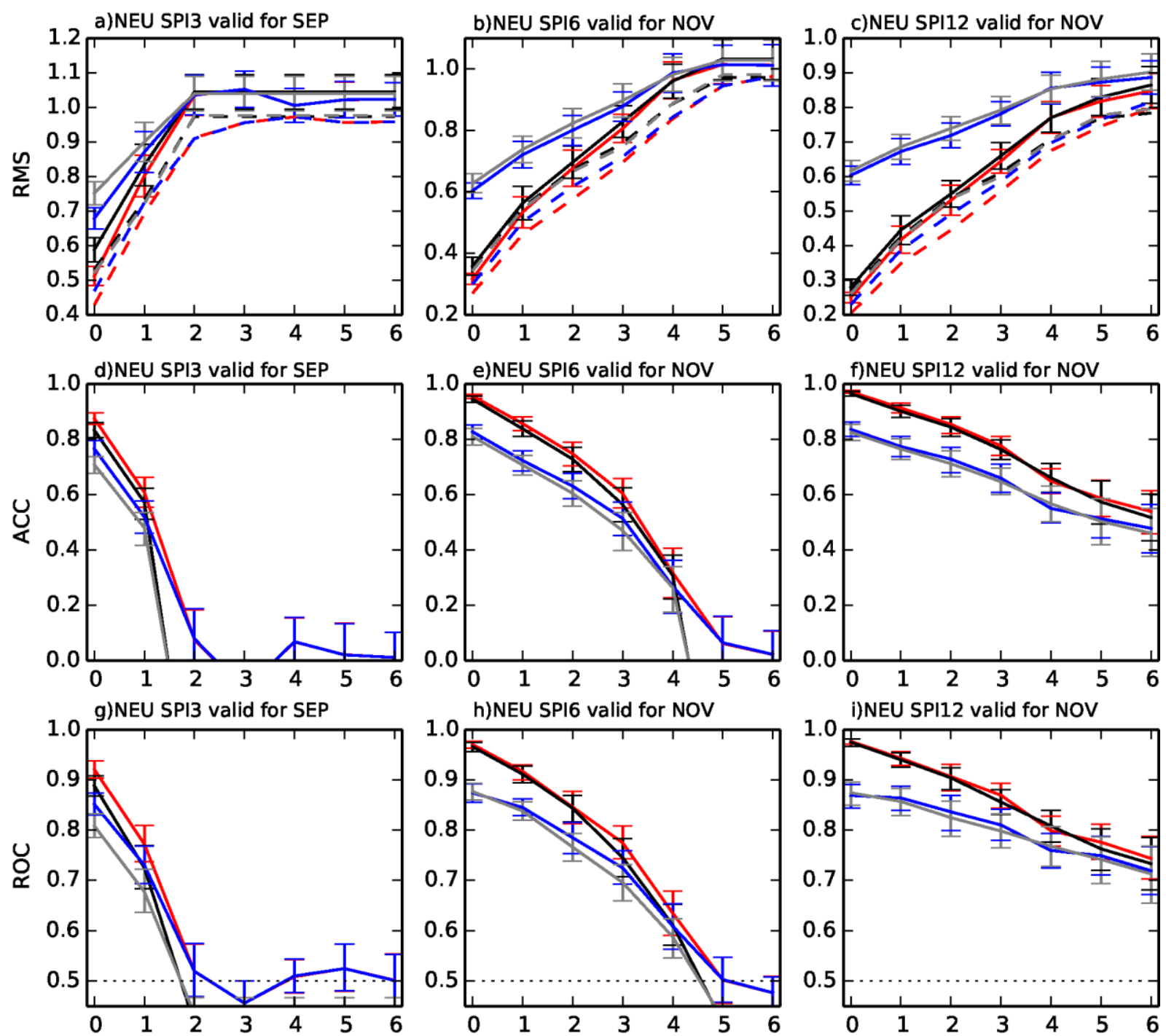

Forecast lead time (months)

Figure S12. As Figure 1 but for the Northern Europe region (NEU). 

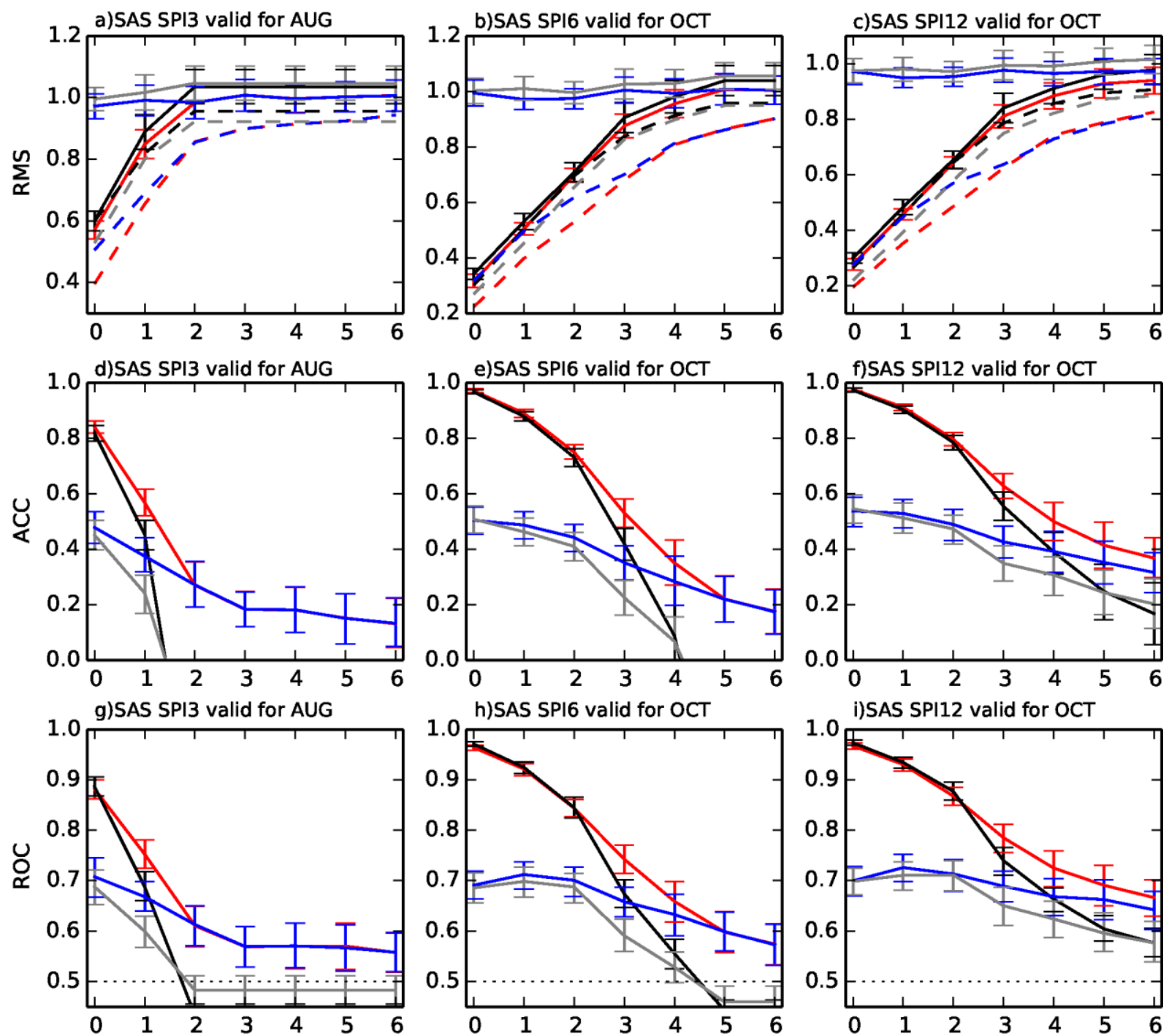

Forecast lead time (months)

Forecast lead time (months) Forecast lead time (months) FI GPCC S4 FA GPCC CLM FA ERAI S4 F士 ERAI CLM

Figure S13. As Figure 1 but for the South Africa region (SAF). 

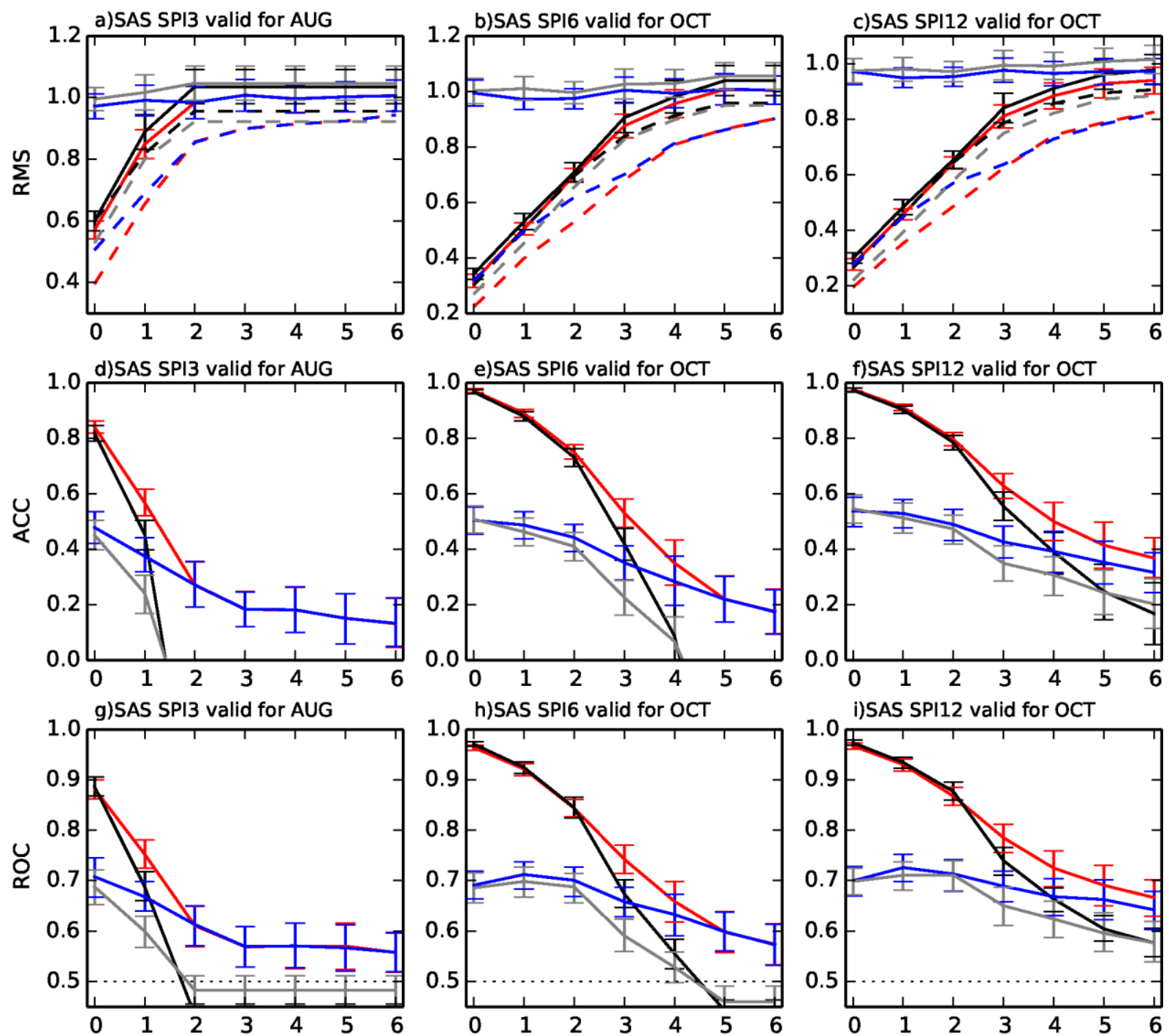

Forecast lead time (months)

Forecast lead time (months) Forecast lead time (months) FI GPCC S4 FI GPCC CLM FA ERAI S4 FI ERAI CLM

Figure S14. As Figure 1 but for the South Asia region (SAS). 

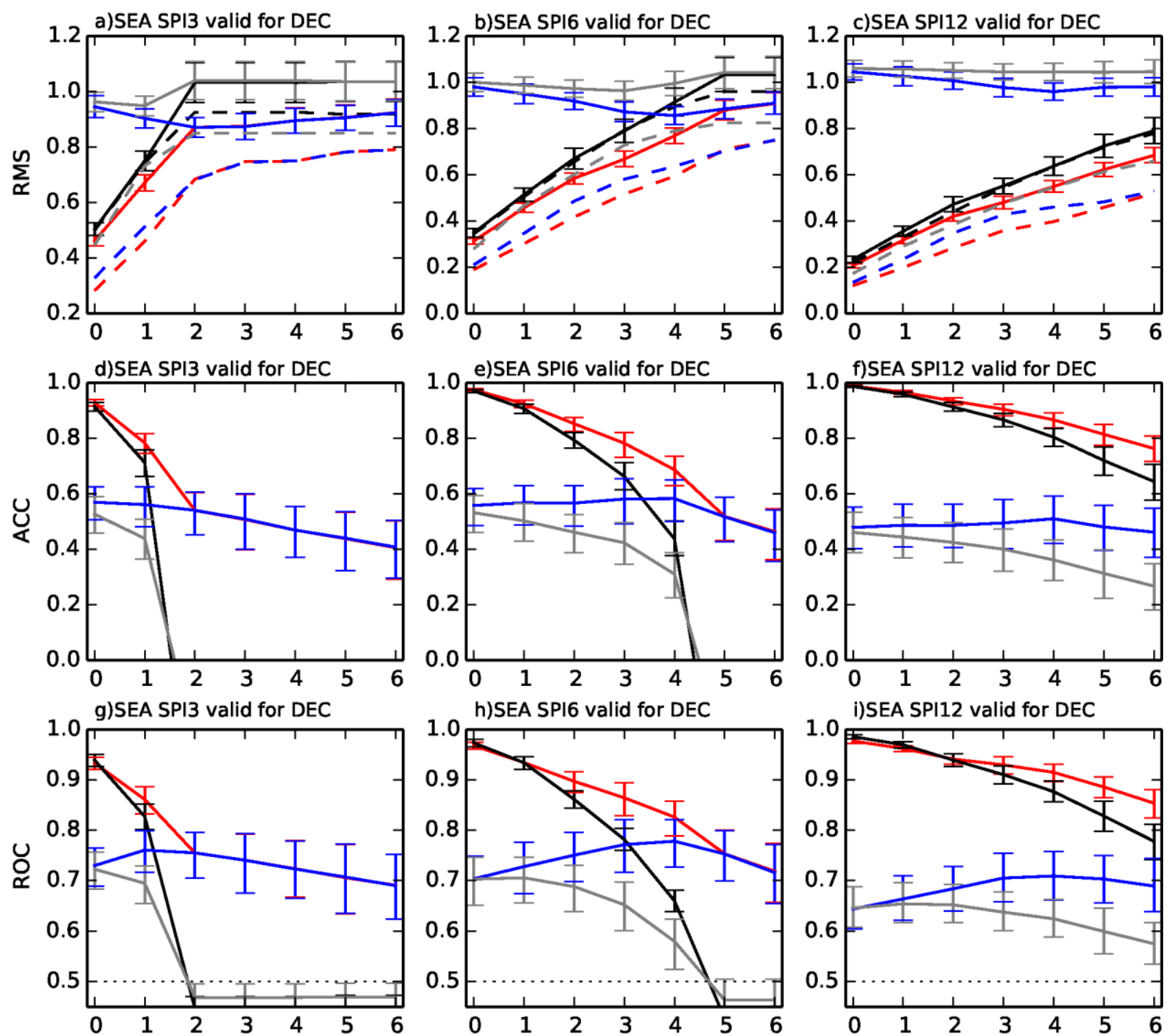

i)SEA SPI12 valid for DEC

Forecast lead time (months)

Forecast lead time (months)

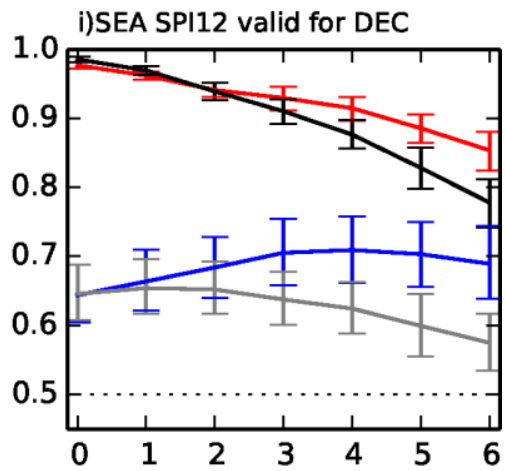

F巫 GPCC S4 FA GPCC CLM F伍 ERA S4

Forecast lead time (months) I ERAI CLM

Figure S15. As Figure 1 but for the South East Asia region (CNA). 

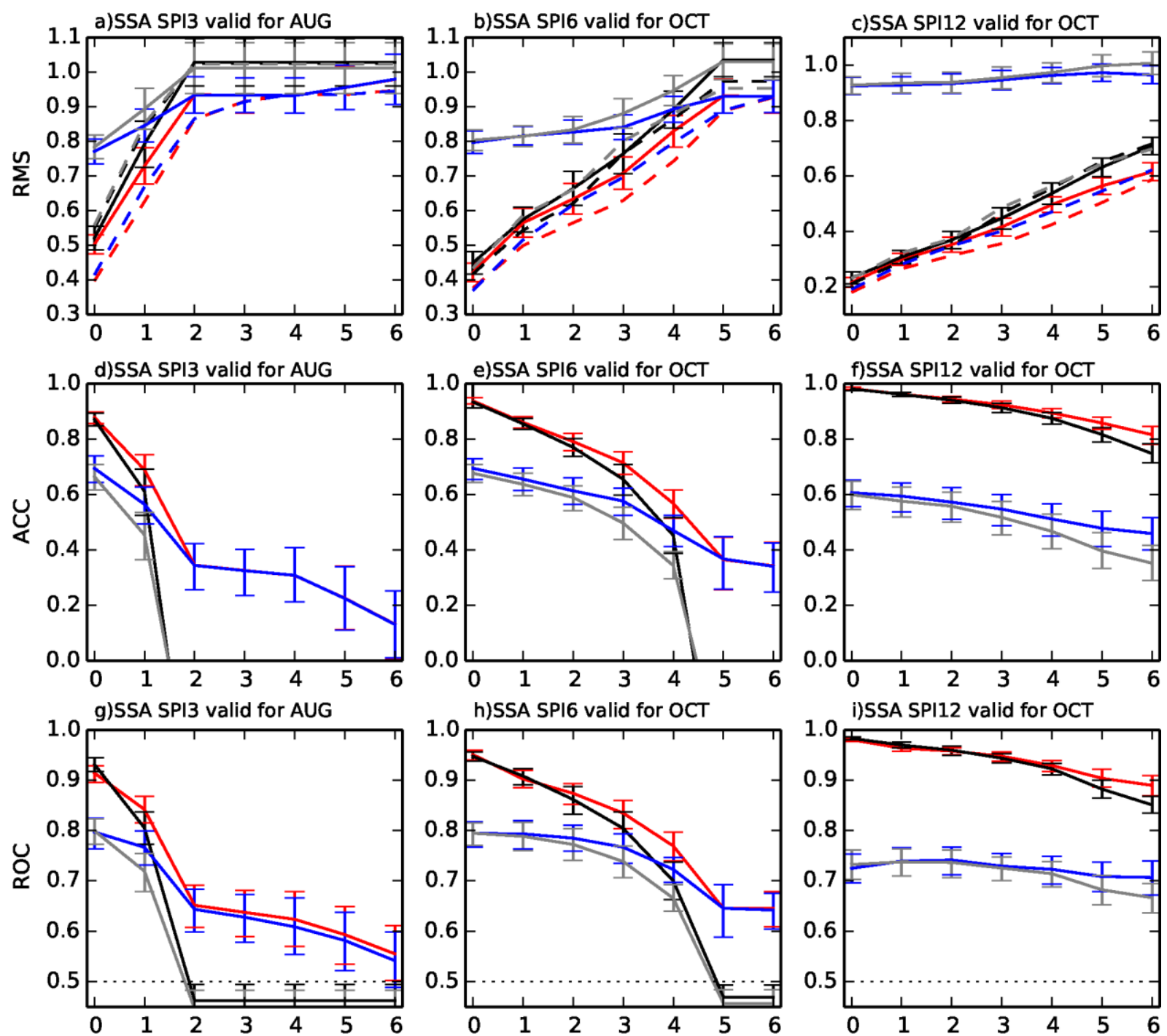

i)SSA SPI12 valid for OCT

Forecast lead time (months)

Forecast lead time (months)

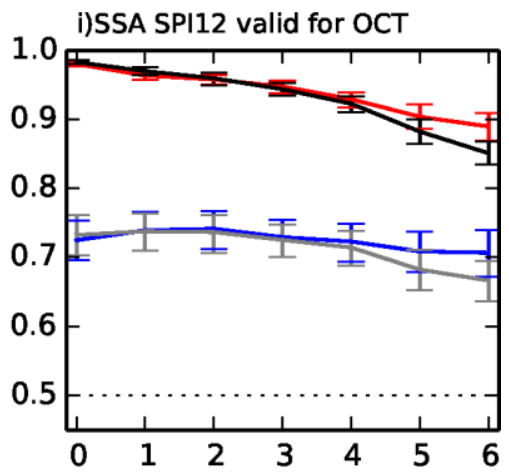

Forecast lead time (months)

FI GPCC S4 FI GPCC CLM FI ERAI S4

EI ERAI CLM

Figure S16. As Figure 1 but for the South South America region (SSA). 

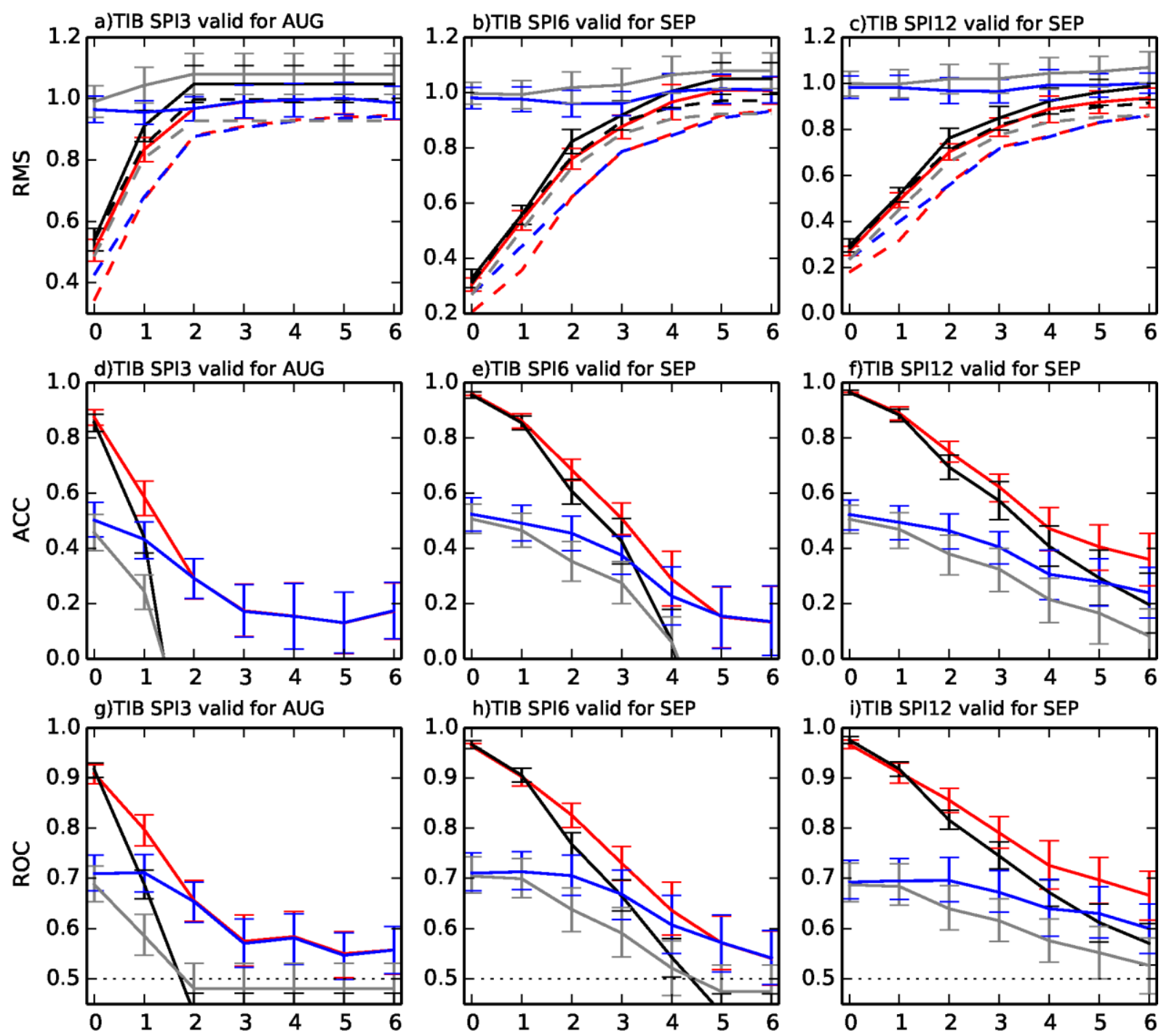

Forecast lead time (months)

Forecast lead time (months) Forecast lead time (months) FI GPCC S4 F士 GPCC CLM FE ERAI S4 F士 ERAI CLM

Figure S17. As Figure 1 but for the Tibet region (TIB). 

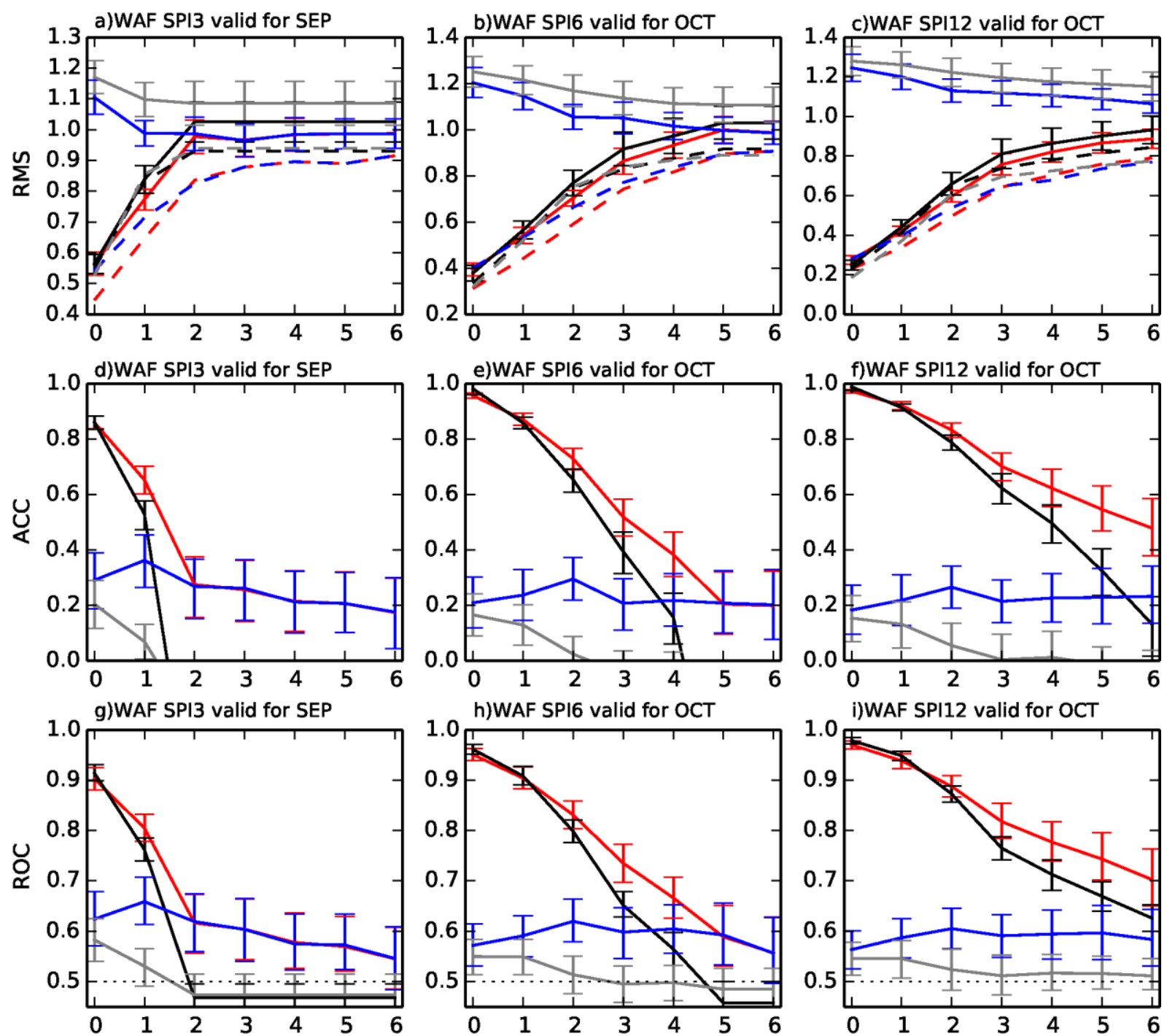

i)WAF SPI12 valid for OCT

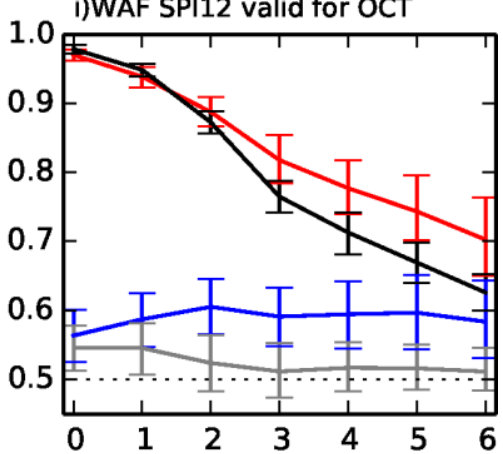

Forecast lead time (months)

Forecast lead time (months) Forecast lead time (months) FI GPCC S4 FA GPCC CLM FA ERAI S4 F士 ERAI CLM

Figure S18. As Figure 1 but for the West Africa region (WAF). 

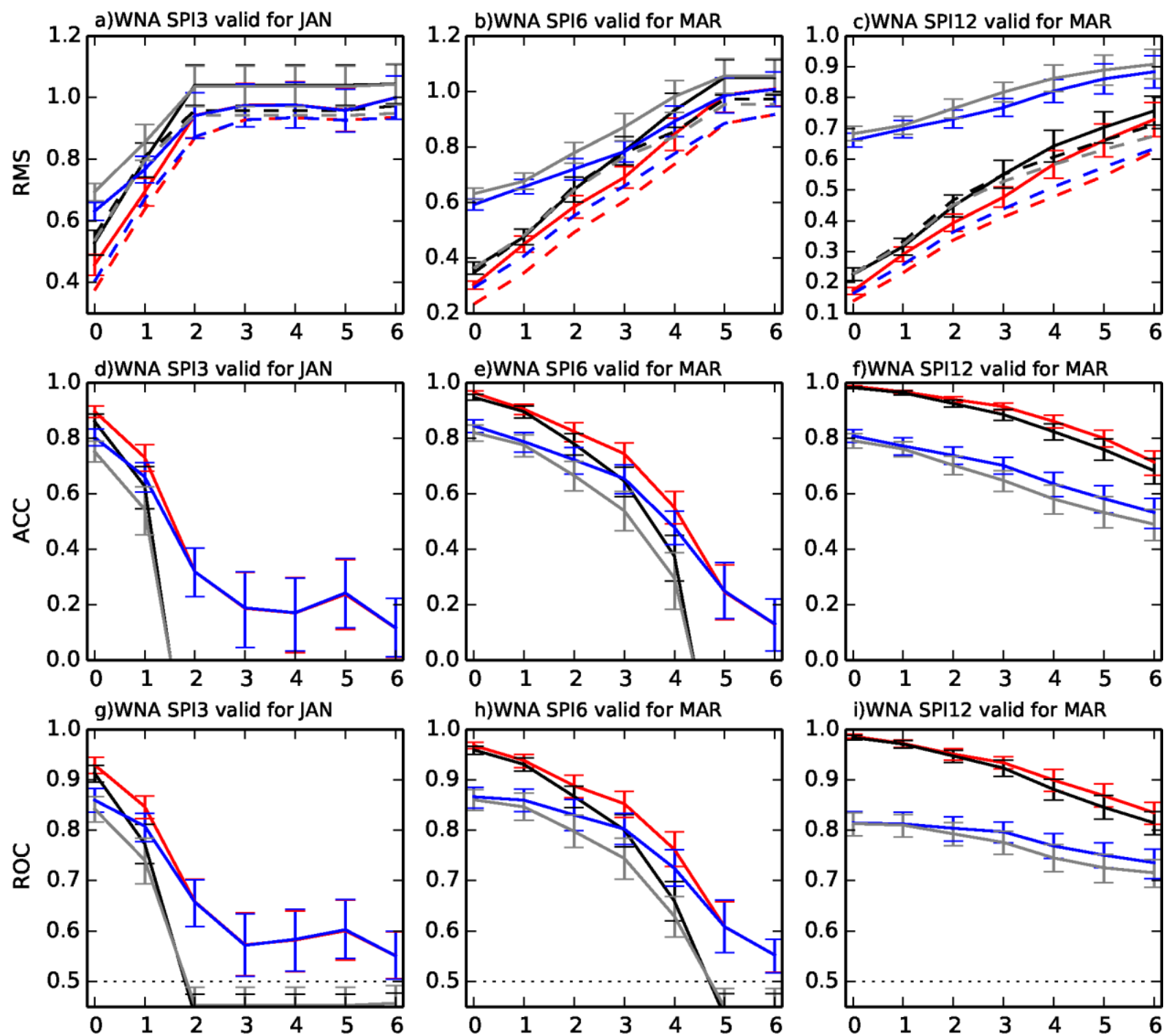

i)WNA SPI12 valid for MAR

Forecast lead time (months)

Forecast lead time (months)

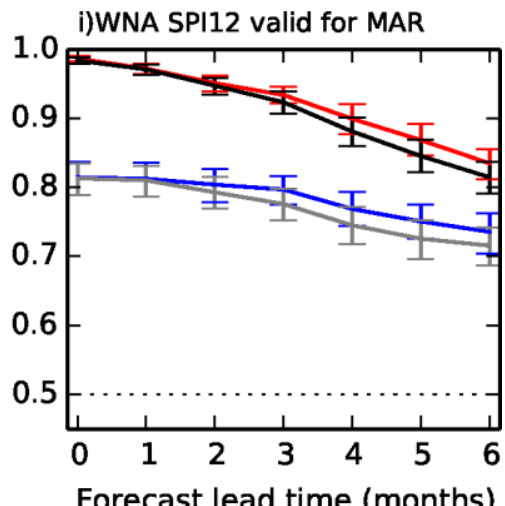

FI GPCC S4 FA GPCC CLM FA ERAI S4 F士 ERAI CLM

Figure S19. As Figure 1 but for the West North America region (WNA). 
(a)

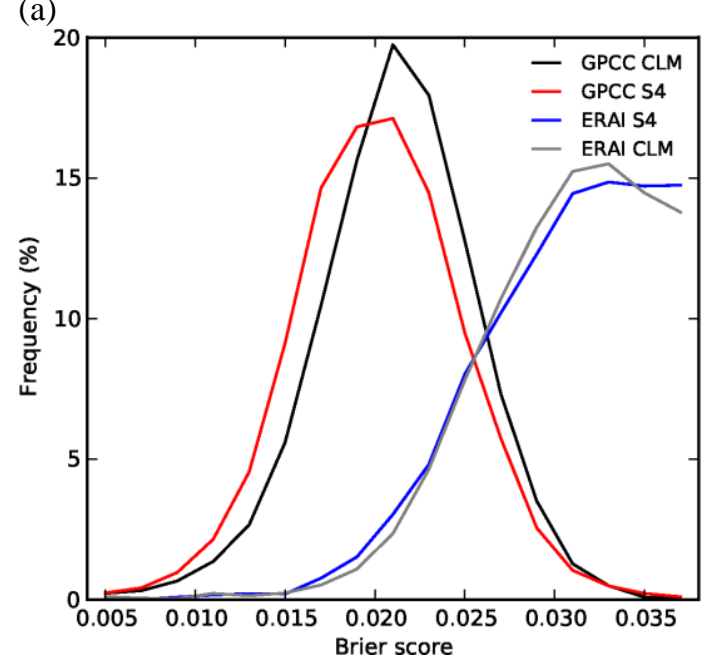

(c)

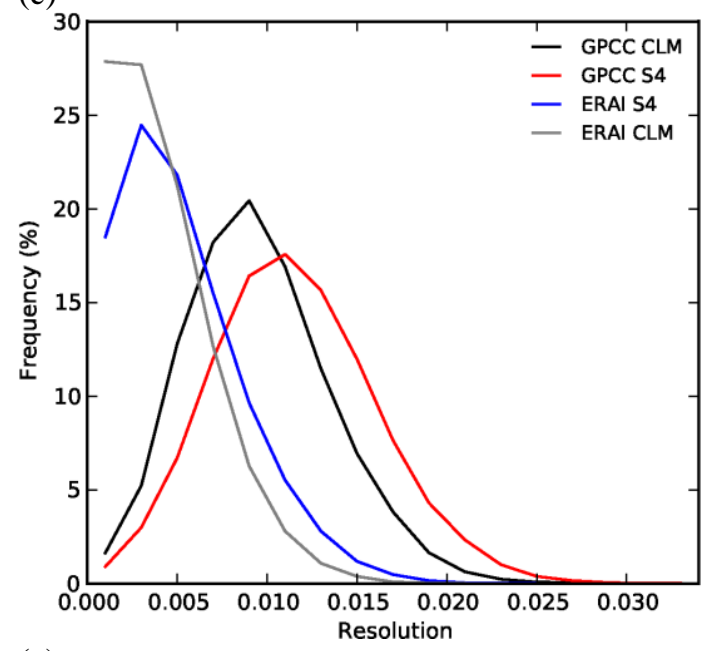

(e)

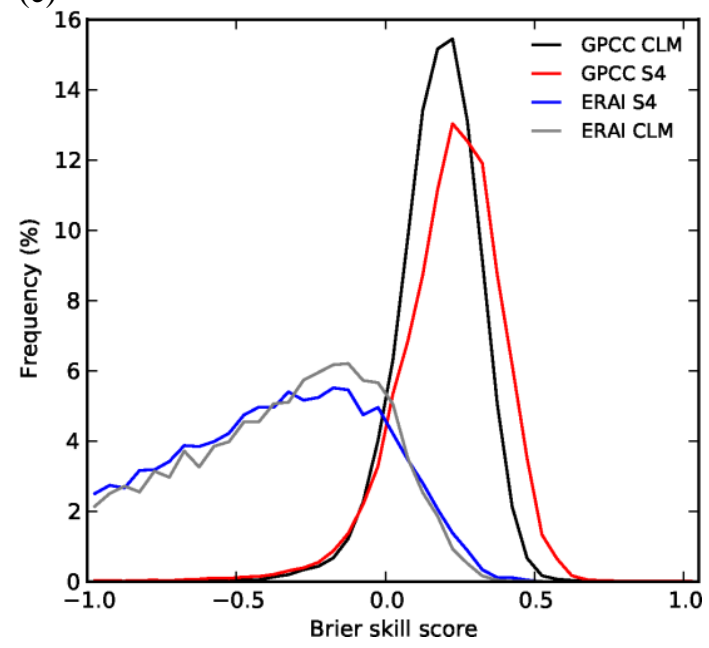

(b)

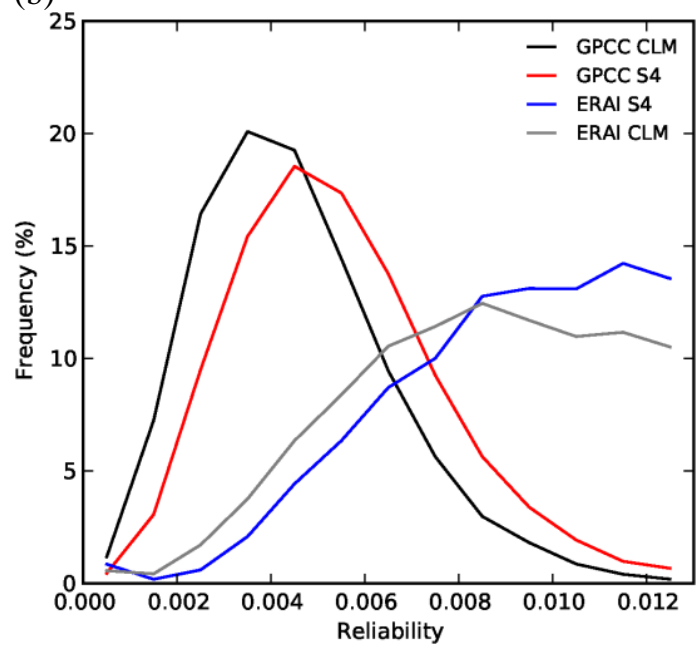

(d)

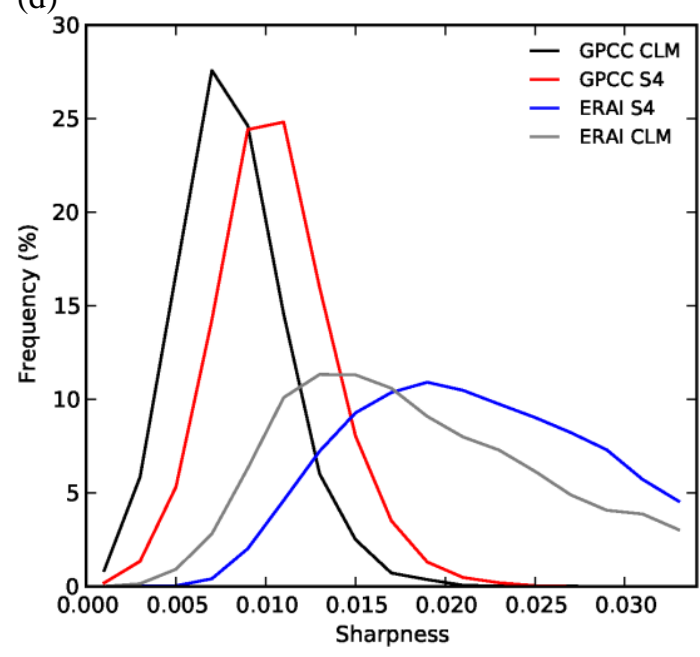

Figure S20. Drough onset frequency distributions of (a) brier score, (b) reliability, (c) resolution, (d) sharpness and (e) brier skill score for the SPI forecasts produced by GPCC S4 (red0, GPCC CLM (black), ERAI S4 (blue) and ERAI CLM (gray). The statististics are based only on land points (similar to Yuan and Wood (2013)), and the reference forecasts for the brier skill score was the climatological frequency of the verification dataset (GPCC). 

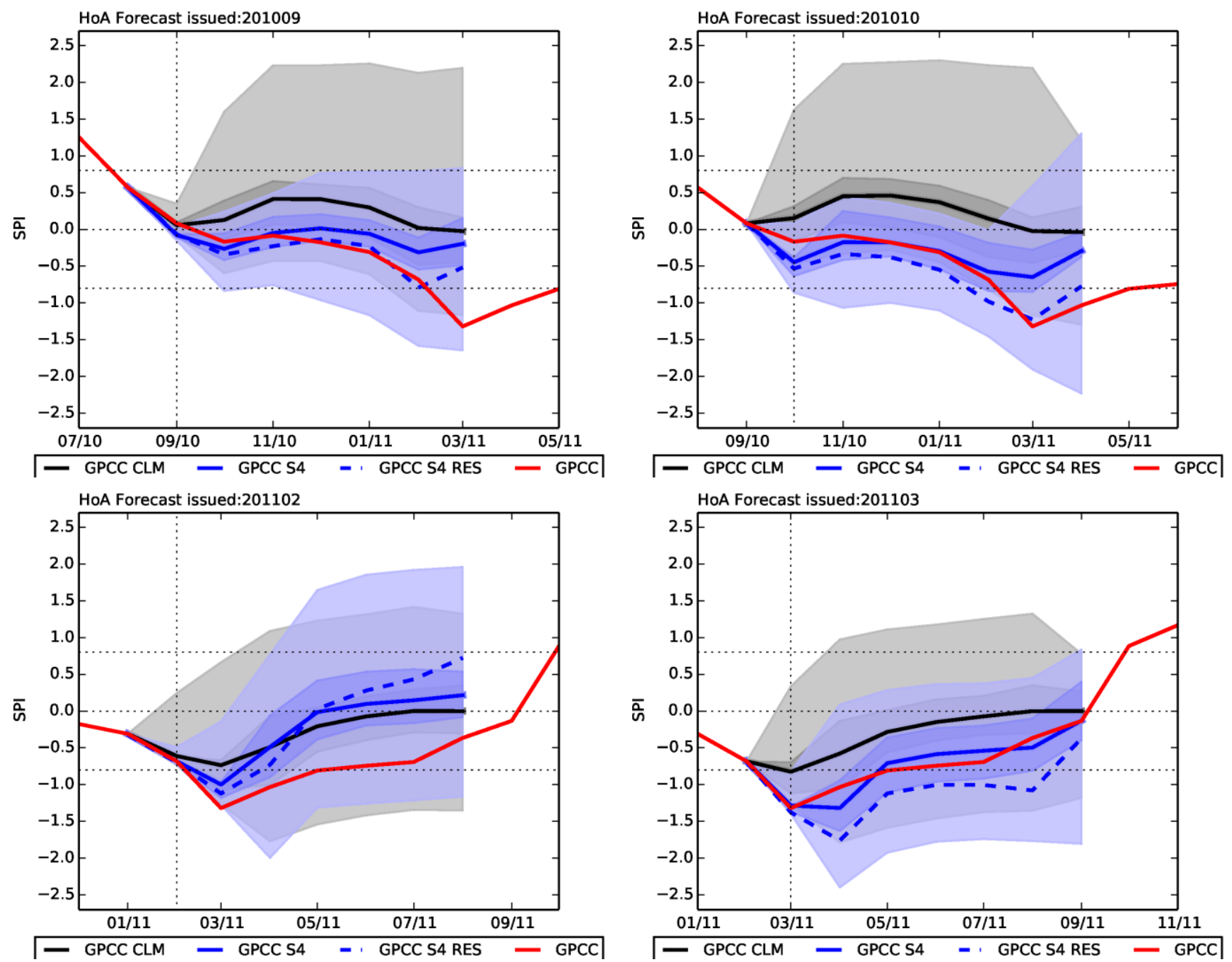

Figure S21. Seasonal forecasts of 6-month SPI in the Horn of Africa region (3S-12N, 40E52E) given by GPCC S4 (blue) and GPCC CLM (black), and the GPCC monitoring (red) issued in September 2011 (top left), October 2011 (top right), February 2012 (bottom left) and March 2012 (bottom right). . The solid lines represent the ensemble mean forecasts of GPCC S4 (blue) and GPCC CLM (black), and the dashed blue line the GPCC S4 ensemble mean rescaled. The shaded areas represent the ensemble distribution between the percentiles 30 to 70 (dark shading) and minimum to maxim (light shading). The horizontal dotted lines denote the $-0.8,0$ and 0.8 SPI values, and the vertical dotted line forecast issue date. 
GPCC S4, Ensemble mean SPI6

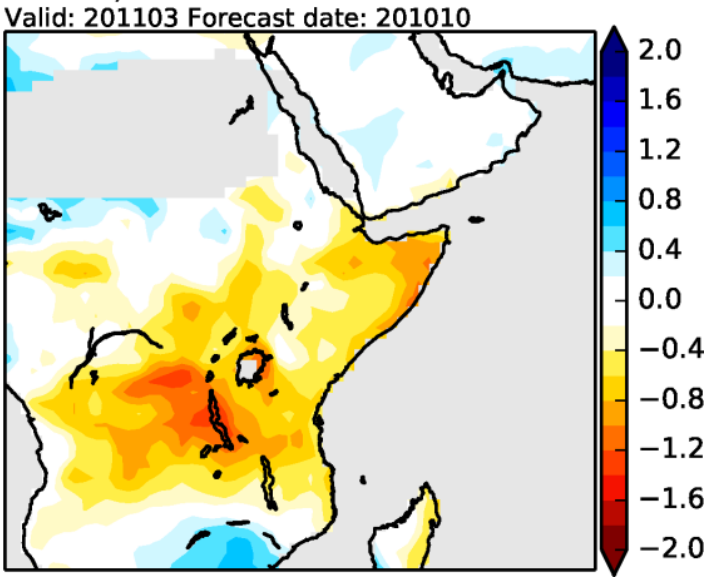

GPCC S4, P>0.8 SPI6

Valid: 201103 Forecast date: 201010
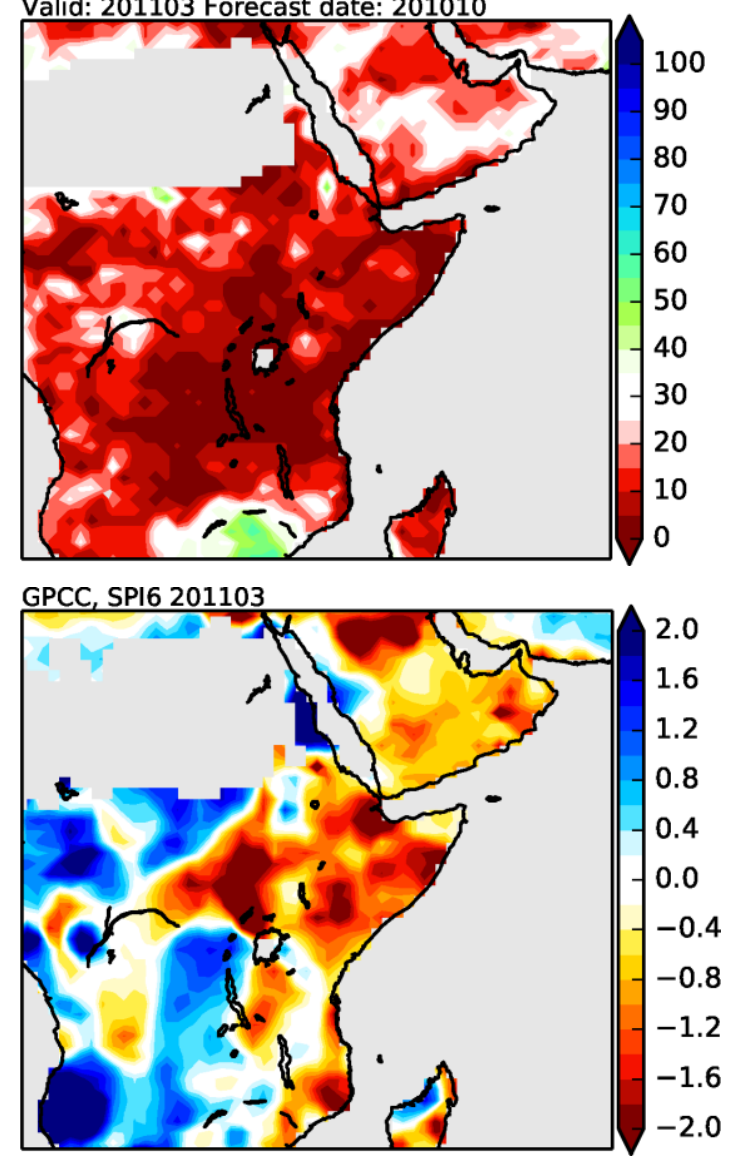

GPCC S4, Ensemble mean Rescaled SPI6

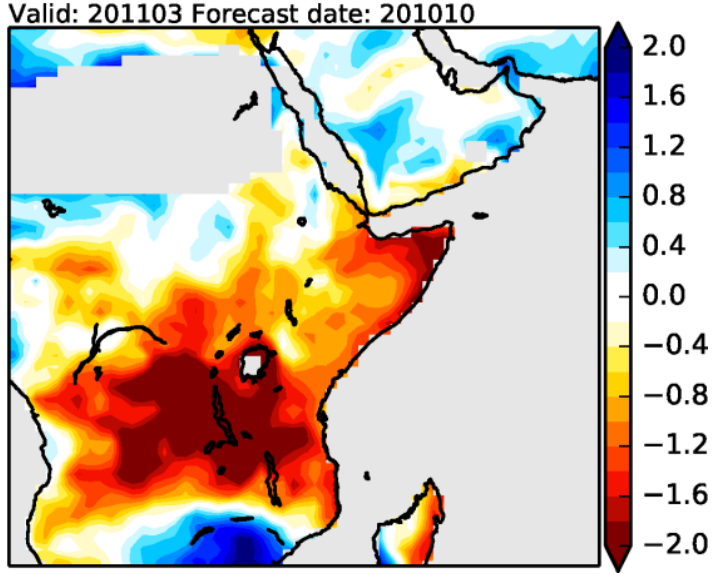

GPCC S4, P<-0.8 SPI6

Valid: 201103 Forecast date: 201010

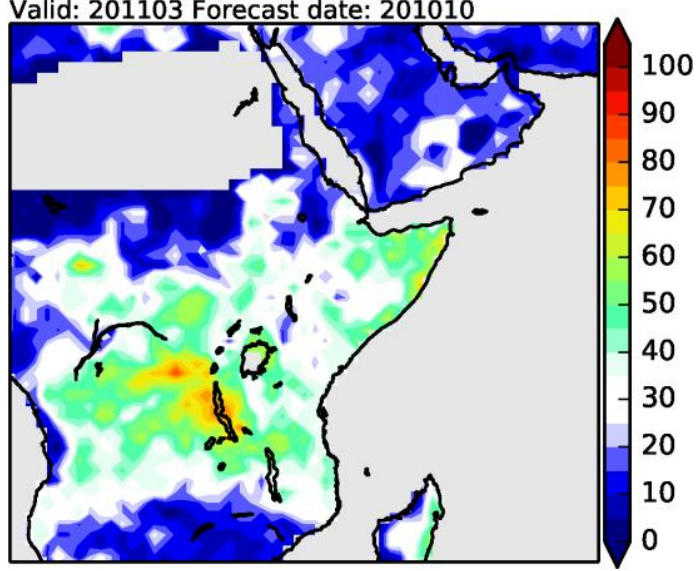

Figure S22. Seasonal forecasts of SPI-6 given by GPCC S4 issued in October 2010 and valid for March 2011: ensemble mean (top left), ensemble mean rescaled (top right), probability of SPI> 0.8 (midle left), probablity of SPI <-0.8 (midle right). Lower panel: SPI-6 in March 2011 from GPCC. In all maps gray denote grid-point where the SPI is not defined. 

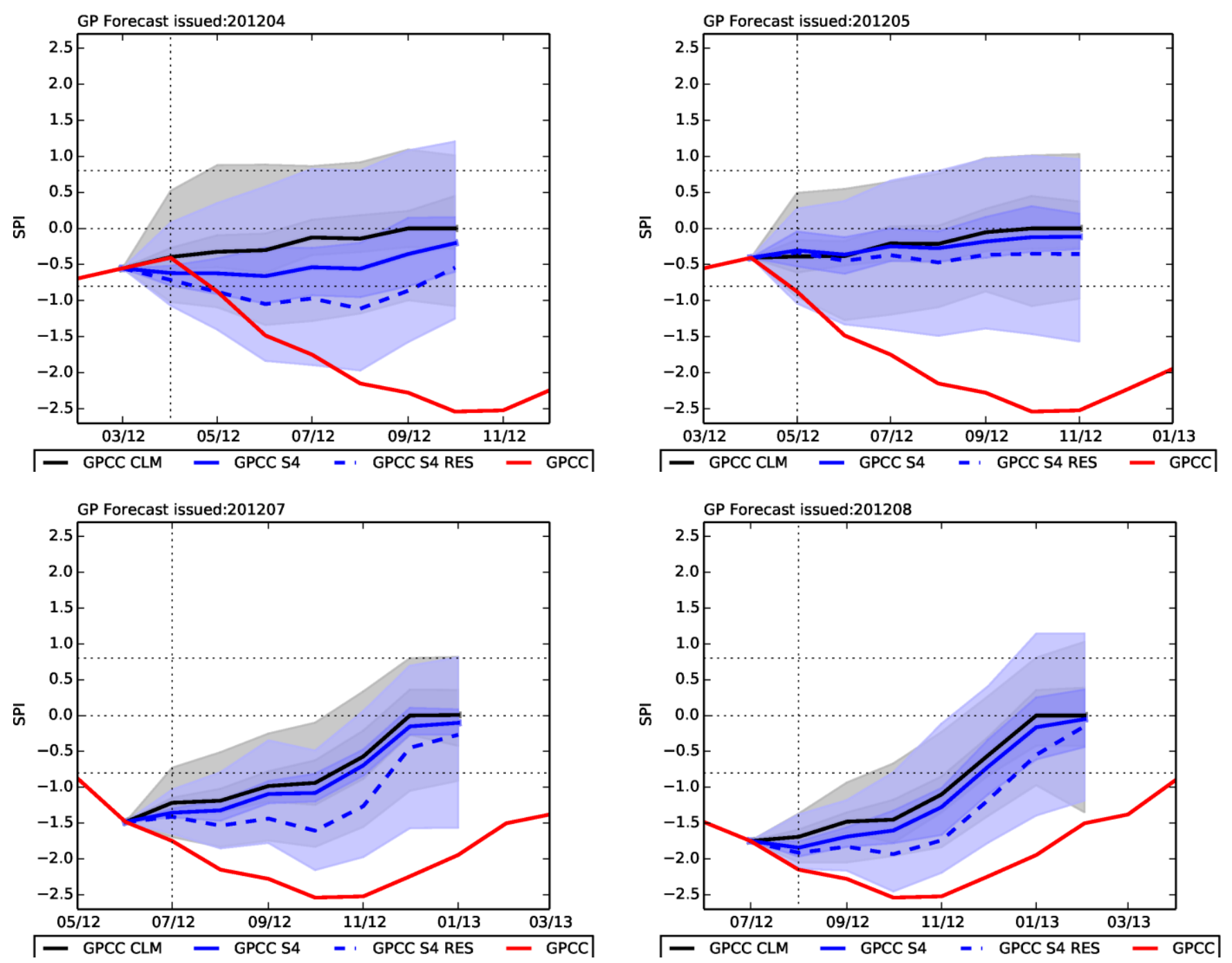

Figure S23. As Figure S21 but for the the SPI-6 forecasts issued in March, May, July and August 2012 for the U.S. Great Plains region ( 35N-45N, 110W-90W). 
GPCC S4, Ensemble mean SPI6

Valid: 201208 Forecast date: 201204
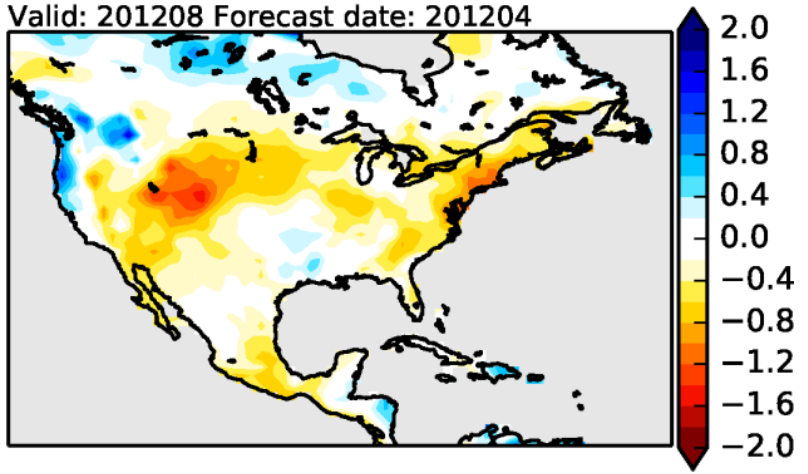

GPCC S4, P>0.8 SPI6

Valid: 201208 Forecast date: 201204

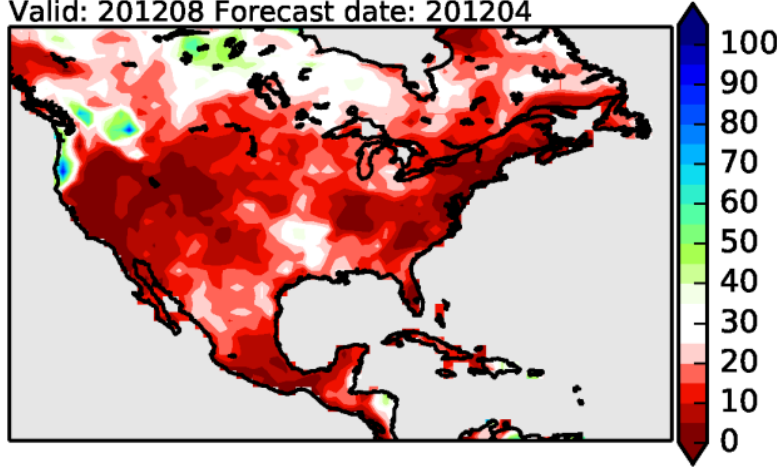

GPCC S4, Ensemble mean Rescaled SPI6

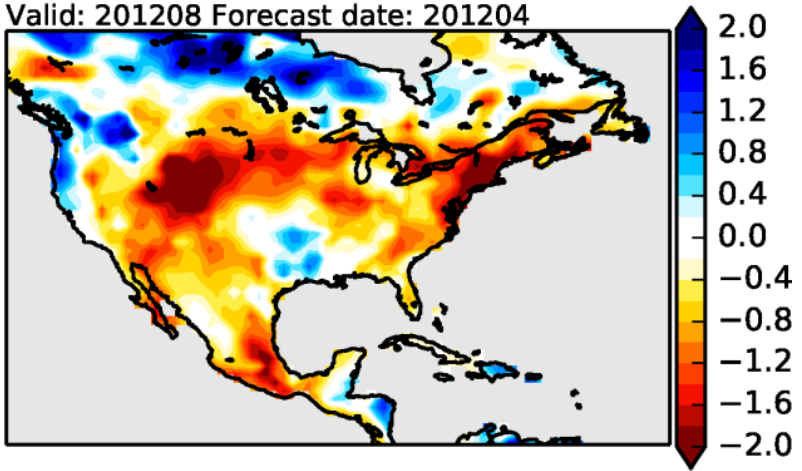

GPCC S4, P<-0.8 SPI6

Valid: 201208 Forecast date: 201204

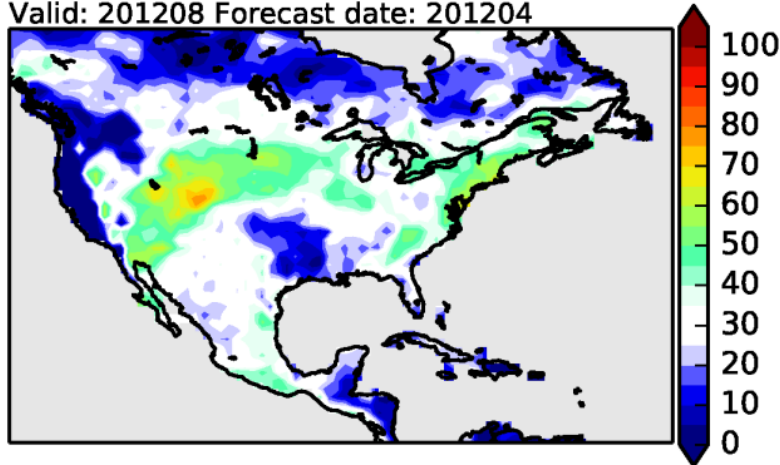

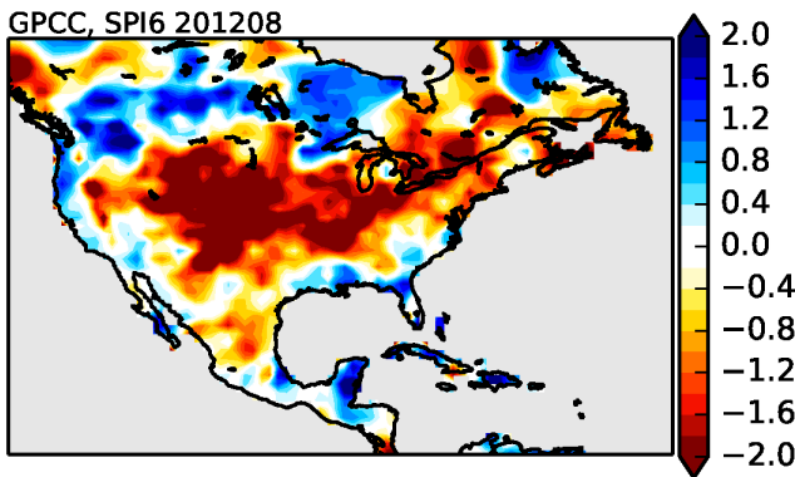

Figure S24. As Figure S22 but for the the SPI-6 forecasts issued in April 2012 and valid for August 2012 in the U.S. Great Plains region (35N-45N, 110W-90W). 